\title{
Organized Growth of Thalamocortical Axons from the Deep Tier of Terminations into Layer IV of Developing Mouse Barrel Cortex
}

\author{
Ariel Agmon, ${ }^{1,3}$ Lee T. Yang, ${ }^{1}$ Diane K. O'Dowd, ${ }^{1,2}$ and Edward G. Jones ${ }^{1,3}$ \\ Departments of ${ }^{1}$ Anatomy and Neurobiology and ${ }^{2}$ Developmental and Cell Biology, University of California, Irvine, \\ California 92717 and ${ }^{3}$ Laboratory of Neural Systems, Frontier Research Program, RIKEN, Wako, Saitama, Japan
}

The thalamocortical projection to rodent somatosensory ("barrel") cortex is highly ordered in both the radial and the tangential dimensions. During a brief period of postnatal development, thalamocortical axons establish two tiers of terminations, in the deep layers and in layer IV, and form whisker-specific clusters within layer IV; however, little is known about the cues that guide them to their appropriate radial and tangential positions. To gain insight into potential mechanisms underlying this process, we studied the development of thalamocortical termination patterns in mouse barrel cortex at high spatial resolution. Developing thalamocortical axons were labeled in fixed slices with the lipophilic carbocyanine dye Dil and imaged with a laser scanning confocal microscope. On the day of birth (postnatal day $\mathbf{0}$, P0) axons coursed through layers $V I$ and $V$, with little or no branching. By P2 the lower tier of terminations, at the border of layers VI and V, was clearly identifiable. Below this tier axons coursed obliquely or tangentially, forming a dense meshwork of intersecting fibers, but with no apparent branching. By P4 the upper tier of terminations, in layer IV, was clearly recognizable, and consisted of periodic, dense clusters of terminal arborizations. In marked contrast to the oblique and apparently disorderly course followed by axons in layer $\mathrm{VI}$ and lower layer $\mathrm{V}$, axons in upper layer $\mathrm{V}$ heading toward the upper tier were organized in loose bundles running radially, suggesting that axons destined to terminate in a particular layer IV barrel had already reached their appropriate tangential coordinates within the lower tier. Thus, the pattern of thalamocortical terminations in layer IV seems to be projected from the deep tier of terminations, and does not develop from an initially profuse arborization pattern through pruning of inappropriate branches.

IKey words: barrel cortex, axonal outgrowth, postnatal development, thalamocortical, corticothalamic, somatotopic map, brain slice, confocal microscopy, Dil]

Axonal projections in the brain are highly ordered, an order that is especially prominent in the topological mapping of sensory receptor sheets onto central brain structures. The mecha-

Received Jan. 25, 1993; revised May 19, 1993; accepted June 24, 1993.

We thank Drs. Casey Annis, Richard Robertson, and Richard Warren for critical reading of an earlier version of the manuscript. Some of the confocal microscopy was done at the Confocal Microscope Facility of the Center for Developmental Biology, U.C. Irvine; we thank Dr. Sue Demaggio of this facility for her technical support. This study was supported by Grants NS30109, NS21377, and AG00096 from the National Institutes of Health, U.S. Public Health Service; by the Frontier Research Program, Japan; by a Bank of America-Giannini Foundation Fellowship to A.A.; and by a University of California President's Undergraduate Fellowship to L.T.Y.

Correspondence should be addressed to Ariel Agmon, Department of Anatomy and Neurobiology, University of California, Irvine, CA 92717.

Copyright $(1993$ Society for Neuroscience 0270-6474/93/135365-18\$05.00/0 nisms by which axonal pathways achieve this high degree of precision during development have been subjects of intensive investigations in a number of systems, but remain largely unknown (reviewed by Dodd and Jessel, 1988). A striking example of topological order in an axonal projection is the spatial organization of thalamocortical terminations in the rodent somatosensory cortex. Along the radial dimension of the cortex, thalamocortical terminations are segregated into two tiers: a diffuse lower tier at the junction of layers V and VI, and a dense upper tier spanning layer IV and lower layer III (Frost and Caviness, 1980; Herkenham, 1980). Within the upper tier, thalamocortical axon arborizations are organized in discrete, periodic clusters or "glomeruli" (Lorente de Nó, 1922), each glomerulus located at the center of an aggregate of cells, or "barrel" (Woolsey and Van der Loos, 1970). When viewed in the tangential dimension of the cortex, the barrels (and glomeruli) form a topological replica of the array of facial vibrissae (Woolsey and Van der Loos, 1970; Killackey and Leshin, 1975). In the rat and mouse, the cellular whisker pad-like pattern first emerges on postnatal day 3 (P3) (Rice et al., 1985), while an equivalent axonal pattern can already be discerned in $\mathrm{P} 2$ rats (Erzurumlu and Jhaveri, 1990). The development of the tangential pattern has also been studied using a variety of markers that display a barrel-like distribution (e.g., Killackey and Belford, 1979; Kristt, 1979; Cooper and Steindler, 1986; Steindler et al., 1989; Erzurumlu et al., 1990; Rhoades et al., 1990; Blue et al., 1991; Jhaveri et al., 1991). Less attention has been given to the development of the radial pattern of thalamocortical terminations (Senft and Woolsey, 1991a). The present study focused on emergence of pattern in the thalamocortical projection by examining the development of the pathway in the radial dimension at high spatial resolution, with particular emphasis on spatial and temporal relationships between the upper and lower tiers as they develop. The study sought to obtain clues to potential mechanisms underlying this developmental process, and to provide a necessary reference point for future studies aimed at testing such potential mechanisms by interfering with normal development. Our results indicate that the highly ordered pattern of thalamocortical terminations in layer IV reflects an order previously established in the lower tier of terminations, and does not arise by pruning of an initially profuse projection.

\section{Materials and Methods}

\section{Tissue preparation}

Animals used were C 57 black mice (Simonsen), from 0 to $12 \mathrm{~d}$ postnatal (P0-P12, P0 being the first $24 \mathrm{hr}$ after birth). Untimed pregnant females were monitored at $12 \mathrm{hr}$ intervals to determine the time of birth. Pups from P0 to P5 were anesthetized by cooling on ice; older pups were anesthetized by halothane inhalation. Anesthetized pups were decapitated, and the brains rapidly removed and placed in ice-cold saline 
Figure 1. Focal dye injections in transilluminated thalamocortical slices. $A$, The anterior (A) face of a P4 slice; dark dots along layer IV (between arrowheads) are DiI injections aimed at the centers of barrels. $B$, The posterior (P) face of a P6 slice; dots in VB are DiI injections. $V B$, ventrobasal complex; $I C$ internal capsule; $S$, striatum; $B C$, barrel cortex; $H$, hippocampus. Arrowheads delimit granular layer IV with identifiable barrels. Direction arrows indicate dorsal $(D)$ and medial $(M)$ orientations. Scale bars, $1 \mathrm{~mm}$.
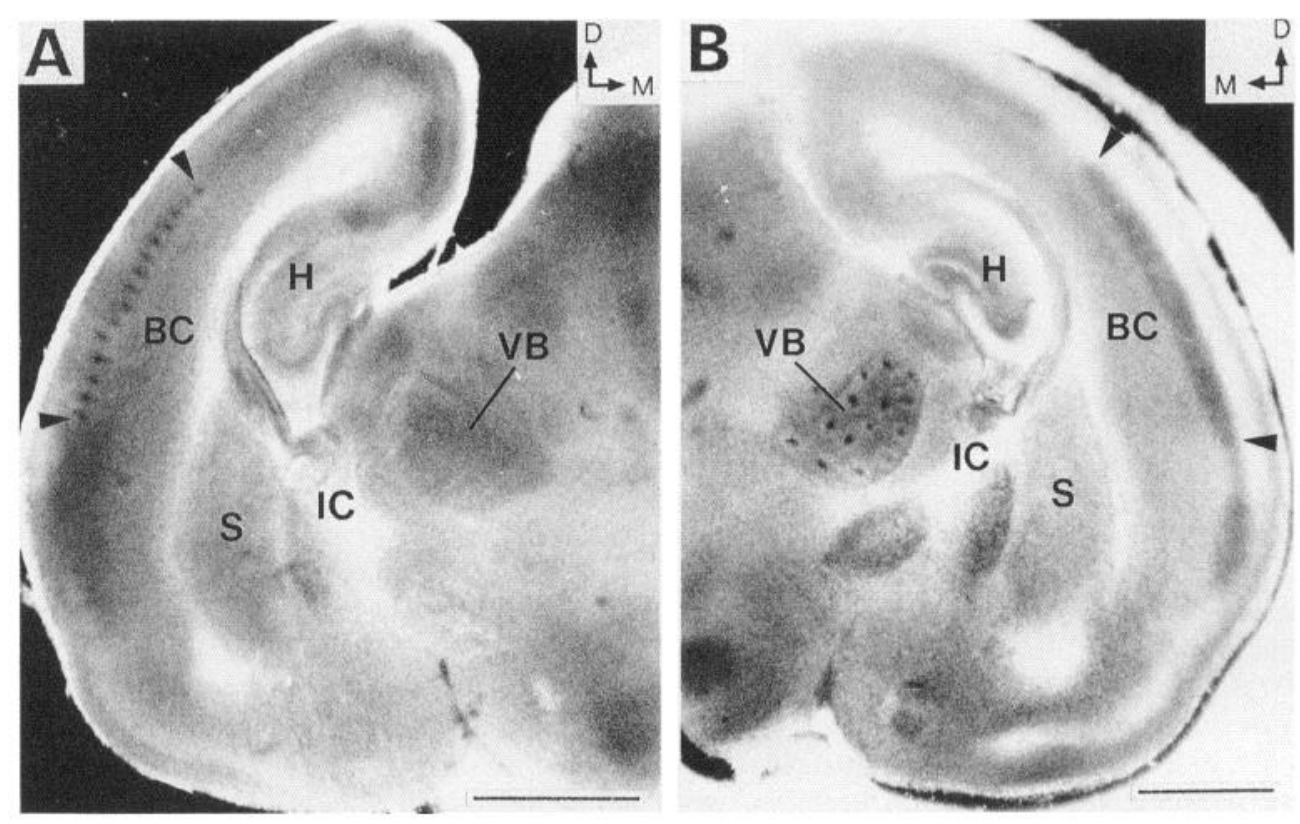

solution. Slices $400 \mu \mathrm{m}$ thick were cut from the right hemispheres on a Vibroslicer (Campden Instruments) in a plane that preserves thalamocortical connectivity, as previously described (Agmon and Connors, 1991). The freshly cut slices were fixed by immersion in $4 \%$ parafor-

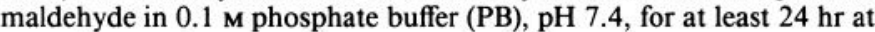
room temperature.

\section{Labeling method}

Slices were labeled with the lipophilic carbocyanine dye 1,1'-dioctadecyl-3,3,3',3'-tetramethylindocarbocyanine perchlorate [DiIC ${ }_{18}(3)$, DiI; Molecular Probes, Eugene, OR]. All dye placements were done under direct visualization through a dissecting microscope; transillumination of the slices allowed identification of the major components of the thalamocortical pathway (Fig. 1). Dye was placed into one surface of the slice only: either the anterior (A-face; Fig. $1 A$ ), or the posterior (Pface; Fig. $1 B$ ). The slice was later imaged from the reverse surface; this reduced the likelihood that labeled structures were due to stray particles of dye that had been dislodged from their original placement site during incubation. Two different methods were used for labeling: bulk labeling with dye crystals was used to visualize the population of thalamocortical fibers as a whole, while focal injections of dye were used to label a small number of thalamocortical fibers, either anterogradely or retrogradely, and thus reveal the course taken by individual fibers. The following three protocols were used.

(1) Bulk labeling in the ventrobasal complex of the thalamus. Fixed slices were washed in $0.1 \mathrm{M} \mathrm{PB}$, laid on a glass slide with their P-face up, and blotted dry. A hand-held tungsten microelectrode was used to place minute particles of DiI on the ventrobasal complex of the thalamus (VB), and to push the particles into the tissue to varying depths.

(2) Focal injections in $V B$. Injections were placed either in fixed slices or in freshly cut slices, the latter being somewhat easier to inject. Slices were placed in a petri dish, P-face up, and immersed in $0.1 \mathrm{M}$ PB. Glass micropipettes were pulled from capillaries $1.5 \mathrm{~mm}$ in outer diameter, their tips were slightly broken under microscopic control, and the pipettes were filled with a solution of $0.5 \%$ DiI in dimethyl formamide (Mallinckrodt, Chesterfield, MO). Small deposits of dye were pressure injected approximately $100 \mu \mathrm{m}$ deep into VB, using a Picospritzer (Gen- eral Valve, E. Hanover, NJ). Individual deposits appeared as red dots when viewed through a stereomicroscope (Fig. $1 B$ ).

(3) Focal injections in cortex. Dye placement in VB obscured details of labeled cells or fibers within and around VB; the initial segment of the thalamocortical pathway was therefore labeled retrogradely in a third series of slices, by focal deposits of dye about $100 \mu \mathrm{m}$ deep into the cortex via the A-face of the slice. Focal injections were aimed at the center of individual barrels, or along the upper third of the cortex in animals at ages before the appearance of barrels (Fig. 1 $A$ ).

\section{Tissue incubation}

Fixed slices with dye deposits were placed individually in vials containing $0.2 \%$ sodium azide in $0.1 \mathrm{M} \mathrm{PB}$, and incubated at $37^{\circ} \mathrm{C}$. Typically, dye was allowed to diffuse for 1-2 weeks in the bulk-labeled material, and for 3-4 weeks in the focally labeled material, before imaging. After imaging, slices were stored in the same buffer at $4^{\circ} \mathrm{C}$. Slices could be successfully reimaged even after a year or more of storage.

\section{Confocal imaging}

Confocal images were obtained using a Bio-Rad (Cambridge, MA) MRC 500 system coupled to an Olympus BH2 microscope, and a Bio-Rad MRC 600 system coupled to a Nikon Optiphot microscope. Slices were imaged as whole-mounts, without resectioning. Optical sections of each slice were taken at 2-10 $\mu \mathrm{m}$ intervals from the surface of the slice through $50-150 \mu \mathrm{m}$ of tissue, using $10 \times(0.5 \mathrm{NA})$ and $20 \times(0.75 \mathrm{NA})$ dry objectives. Stacks of optical sections (typically 10-20 per field) were digitally superimposed and then printed in reverse contrast (black on white) using a Sony Mavigraph videoprinter. Montages were reconstructed from prints corresponding to partially overlapping microscopic fields. Individual frames were also photographed from the screen using a $35 \mathrm{~mm}$ camera.

\section{Nissl staining}

The prolonged incubation of many of the DiI-labeled slices rendered them too fragile for resectioning; Nissl staining was therefore performed on slices prepared from age-matched animals using the same procedure

Figure 2. Cytoarchitectonic development of mouse barrel cortex, as seen in Nissl-stained thalamocortical slices from P0 through P8. Each of the panels in the top row is a high-power view of the region between arrowheads on the low-power photomicrograph below. All upper panels are aligned according to layer VIb at the bottom. Note that the increase in cortical thickness between P0 and P2 is mostly due to expansion of the deep layers, while subsequent increase is mostly due to the emergence of layers IV-II out of the undifferentiated cortical plate. Roman numerals denote cortical layers; $C P$, undifferentiated cortical plate. Direction arrows are as in Figure 1. Scale bars on top right (100 $\mu \mathrm{m})$ and bottom right panels (1 mm) apply to all top and bottom panels, respectively. 

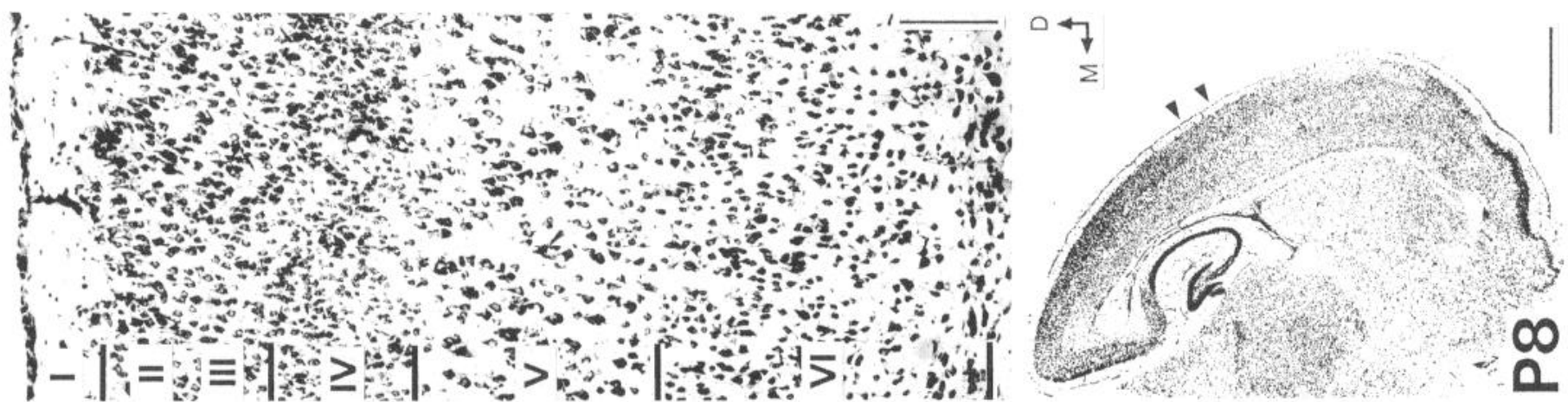

to $b$ a 4 ?

5 as 8 si

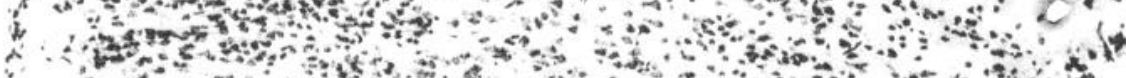

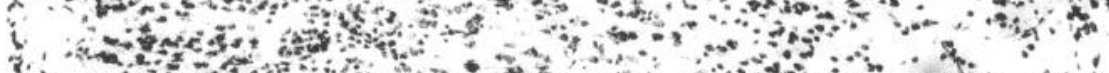

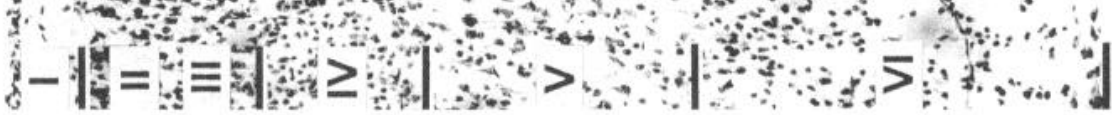

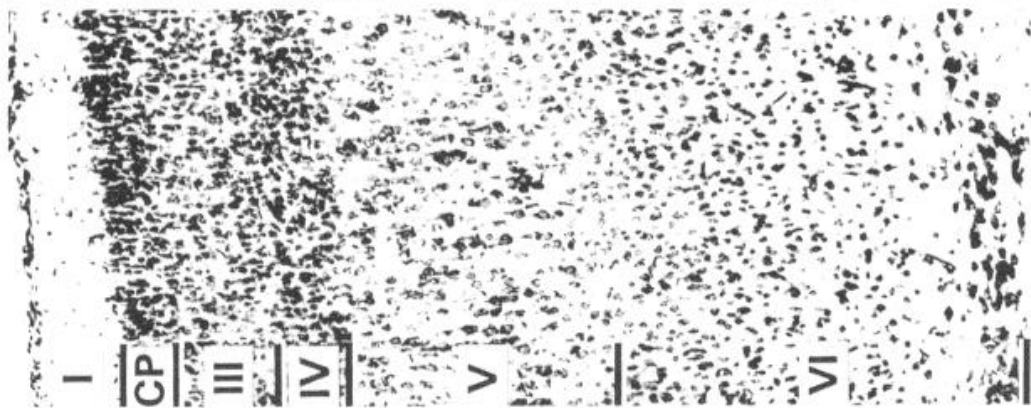

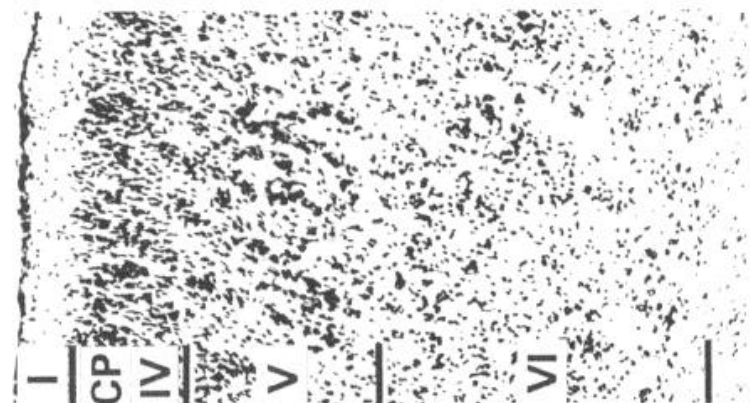
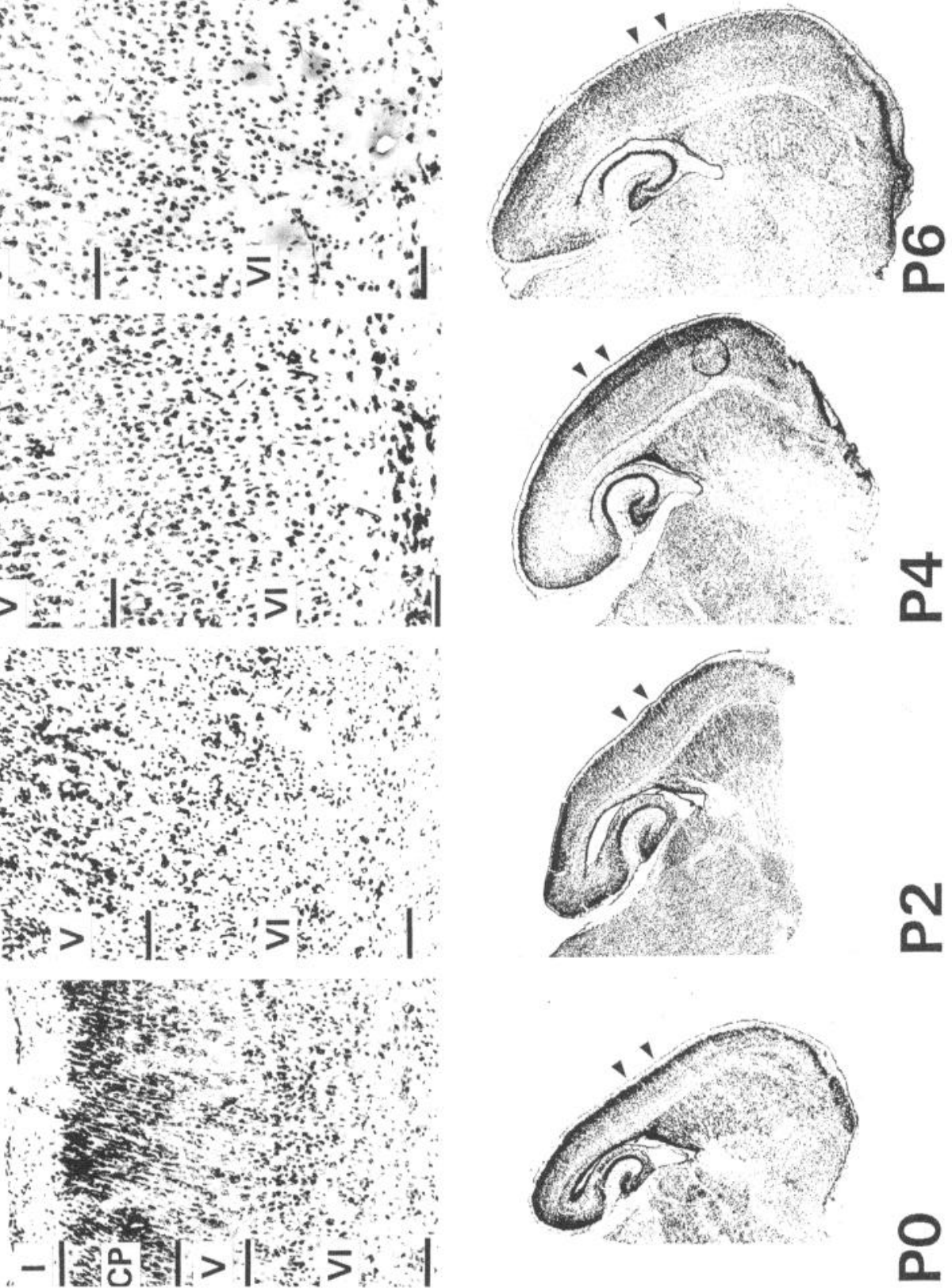
Figure 3. Labeling patterns resulting from bulk dye placements in VB. $A$ and $B$, Low-power confocal images of the A-face $(A)$ and P-face $(B)$ of a $\mathrm{P} 3$ slice. The A-face includes predominantly anterogradely labeled thalamocortical axons, while the P-face includes predominantly retrogradely labeled corticothalamic cells (note their restricted laminar distribution in the deep layers and the parallel, nearly radial trajectories of their descending axons). Rightangle arrows denote the predominant orientation of thalamocortical axons, coursing dorsomedially in the white matter and then turning up toward the pial surface. $C$, Labeled fiber bundles in the striatum and white matter, in a P8 slice. Arrowheads point to the deep border of the subcortical white matter, where most dorsomedial fibers (right arrowhead) turn dorsomedially, but ventrolateral fibers (left arrowhead) initially turn ventrolaterally before looping back in a U-shaped trajectory. Direction arrows are as in Figure 1. Scale bars, $250 \mu \mathrm{m}$.
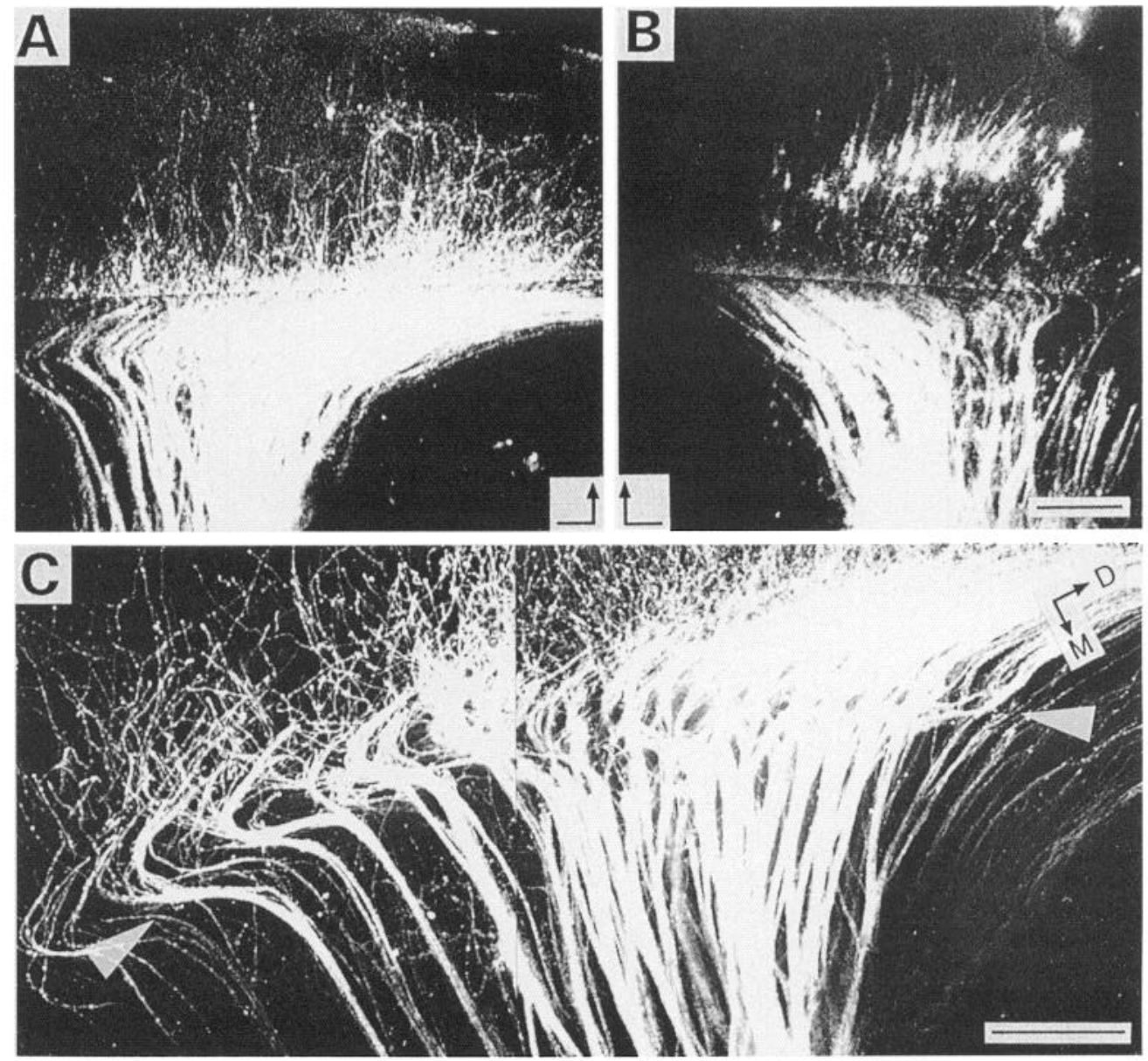

described above, except that slices were cut at $800 \mu \mathrm{m}$. After fixation, slices were washed for $1-4 \mathrm{hr}$ in $20 \%$ sucrose in $0.1 \mathrm{M}$ PB, embedded in Tissue Tek (Miles Inc., Elkhart, IN), and resectioned on a cryostat at $20-40 \mu \mathrm{m}$. Sections were collected and air dried overnight on slides subbed with Vectabond (Vector Laboratories, Burlingame, CA), and then were stained with cresyl violet, dehydrated in graded alcohols, cleared, and coverslipped. Laminar borders were measured with an eyepiece reticle, normalized to total cortical thickness, averaged from at least three different animals from each age, and matched with DiIlabeled slices from the same age.

\section{Results}

A total of 121 animals, between P0 and P12, were used in this study. Typically two or three slices from each animal were labeled with DiI; however, no more than one slice per animal was found after incubation to contain labeled axons running uninterrupted from VB to the barrel cortex. Approximately 1200 confocal images were acquired from 51 slices that contained an uninterrupted thalamocortical pathway.

\section{Cytoarchitectonics of neonatal barrel cortex examined in the thalamocortical plane of section}

The nonstandard plane of section used in the present study required us to examine the Nissl pattern in this plane, to allow determination of the laminar position of DiI-labeled thalamocortical axons at each developmental stage. Nissl-stained thalamocortical slices (Fig. 2) showed a pattern of cytoarchitectonic development similar to that previously described in the coronal plane of section (Rice and Van der Loos, 1977). By birth the deeper $60 \%$ of the cortex was occupied by layers VI and V, with the rest of the cortical mantle divided between the undifferentiated cortical plate and the cell-sparse marginal zone (presumptive layer I). By P2 there was a considerable expansion of layers VI and V, in some preparations to about $75 \%$ of the cortical thickness; the deeper part of the cortical plate was separated from layer $\mathrm{V}$ by a transition zone characterized by very small cells that comprised the incipient layer IV. By P4 layer IV could be clearly distinguished both from layer $\mathrm{V}$ and from a nascent layer III by the small size of the cell bodies that comprised it and by its higher cell density; the undifferentiated cortical plate had shrunk to become a few cells thick. At this stage layers IV and III and the remaining undifferentiated cortical plate comprised the "trilaminar cortical plate" of Rice and Van der Loos (1977). By P6, virtually nothing remained of the undifferentiated cortical plate, and its remnants had become layer II. A further expansion in cortical thickness between P4 and P12 was mainly due to an increase in the thickness of layers II-IV, with almost no change in the thickness of the deeper layers. In preparations older than P4, barrels could be identified as periodicities in cell density within layer IV.

\section{Segregation of anterogradely and retrogradely labeled elements}

When dye was placed in VB, a spatial separation occurred between anterogradely and retrogradely labeled elements in the cortex: close to the anterior surface of the slice (A-face; Fig. $3 \mathrm{~A}$ ), 
the majority of labeled elements were anterogradely labeled thalamocortical axons, while close to the posterior surface (P-face; Fig. $3 B$ ), most labeled elements were retrogradely labeled corticothalamic cells (and their axons). This separation was no doubt a consequence of the spatial relationships between the specific plane of section used in this study and the trajectories of the afferent and efferent fiber systems (see Discussion). By scanning the slices from their A-face we were thus able to acquire images with a relatively pure population of anterogradely labeled thalamocortical axons.

\section{The thalamocortical pathway-a topographical description}

The following description of the thalamocortical pathway is in topographical order, outlining the different components of the pathway from VB to the barrel cortex, illustrated by examples chosen without regard to developmental order. In a subsequent section we describe in detail the day-to-day sequence by which the different components appeared.

\section{The subcortical segment of the pathway}

The subcortical segment of the thalamocortical pathway was visualized both by anterograde labcling of thalamocortical axons from dye placement in VB (Fig. $3 C$ ), and by retrograde labeling of thalamocortical cells and axons from dye injections in the superficial and middle cortical layers (Fig. 4). As early as P0, dye injections into the superficial or middle cortical layers resulted in retrogradely labeled cells in VB (Fig. 4). Labeled cells were usually found in the dorsal part of the internal (medial) division of VB. Retrogradely labeled VB neurons were multipolar, often with radially asymmetric dendrites. In some of the preparations, another population of retrogradely labeled cells was found medial to VB, in the posterior medial nucleus of the thalamus (POm) (not shown). The number of labeled cells in POm was usually very small (typically fewer than five), and always far fewer than the number of cells labeled in VB (typically 50). Labeled thalamocortical axons most often left VB to reach the internal capsule by the shortest route possible, that is, ventrolaterally, traversing the external division of VB in parallel trajectories (Fig. $4 A, B$ ) and crossing through the thalamic reticular nucleus (RTN), where they issued fine collateral branches that formed a plexus transverse to the main axonal trunks (Fig. $4 A, B$, between arrowheads). Labeled thalamocortical axons leaving the RTN converged into a narrow isthmus within the internal capsule (Fig. $4 A, B$, between asterisks), abutting the lateral corner of the lateral ventricle. Beyond this point labeled fibers aggregated in bundles that followed diverging trajectories through the striatum (Figs. $3 C, 4 B$ ). These bundles defasciculated as they entered the subcortical white matter (Fig. $3 C$, between arrowheads; Fig. $4 B$, open arrow).

\section{The intracortical segment of the pathway}

The intracortical part of the pathway was visualized by anterograde labeling of thalamocortical axons from dye placements in VB. In slices from $\mathbf{P} 4$ and older animals, labeled thalamocortical afferents comprised five laminar zones within the barrel cortex. These five zones are labeled A-E in Figure 5, in an inside-out sequence, and are described in the same order below. Two of these zones (zones B and D in Fig. 5) consisted of labeled terminal arborizations and formed the lower and upper tiers of terminations, at the layer VI/V border and in layer IV, respectively. The three zones below, between and above the two tiers of terminations consisted of unbranched labeled axons: a dense meshwork of axons in lower layer VI (zone A), radially oriented bundles of axons in upper layer $\mathrm{V}$ (zone $\mathrm{C}$ ), and terminal segments of axons in layer II/III (zone E). Individual elements from different zones are illustrated in Figures 6 and 7.

Lower layer VI: dense fiber meshwork. Labeled thalamocortical axons entered the cortex in one of two ways. The great majority of labeled axons entered the cortex without branching, by curving upward; the angle of the initial curve taken by such axons varied considerably, from shallow (Fig. 6A, arrows), to a right angle (Fig. $6 B$ ), to acute (Fig. $6 C$ ). In a very small number of cases, labeled thalamocortical axons coursing in the white matter were observed to give off a branch that ascended into the cortex, while the main trunk continued in its tangential course in the white matter (Fig. $6 D$ ). However, the ascending branch was never observed to leave layer VI. Due to the variety of angles of entry into the cortex, the labeled thalamocortical axons in lower layer VI formed a meshwork of densely interwoven fibers running in all directions (Fig. 5, zone A). Despite the difficulty in following individual axons within this meshwork, careful inspection of our confocal images revealed that axons in this zone never emitted long branches. Occasionally, labeled axons emitted short protrusions, but these were seldom more than $5 \mu \mathrm{m}$ long.

Upper layer VI/lower layer $V$ : lower tier of terminations. In P2 and older preparations, this zone was more densely labeled than the regions above and below it, primarily due to fine branches and terminal arborizations, the latter having a faint, punctate appearance in the confocal images (Fig. 5, zone B). Retrogradely labeled corticothalamic cells, when present, were also located within this zone. The terminal arborizations of this zone comprised the lower tier of thalamocortical terminations. In a small number of preparations, mainly from focally injected slices, individual thalamocortical axons were labeled in isolation. Some of these axons were seen to emit both a lower-tier arbor (Fig. 7A, between asterisks) and an upper-tier arbor (Fig. $7 A$, between stars); however, it could not be ruled out that some thalamocortical axons arborized only in one of the two tiers. A distinctive feature of the lower tier was the many labeled axons that coursed horizontally within it for several hundred micrometers (Fig. $6 E$, axon denoted by arrows). Such axons were never seen to emit multiple, widely separated branches along their tangential course. Most of these horizontal axons eventually curved toward the upper layers, sometimes after emitting a few branches in the lower tier of terminations (Fig. $6 E$, upper right).

Upper layer $V$ : radially coursing bundles. This zone, and the two zones above it, were distinguishable in all specimens P4 and older. Labeled axons in this zone had virtually no branches, only main trunks that, with few exceptions, coursed radially upward (Fig. 5, zone C). The labeled axons were loosely grouped in bundles 50-200 $\mu \mathrm{m}$ wide, each bundle leading to a cluster of terminal arborizations in layer IV (see below). The majority of labeled axons stayed within a single bundle; a small minority crossed from one bundle to the next. Some labeled axons bifurcated within this zone (Fig. $7 \mathrm{C}$ ), but the two daughter branches ascended in parallel to layer IV, and always formed overlapping terminal arborizations within the same layer IV cluster. Regions containing few or no labeled processes separated adjacent bundles.

Layer IV: upper tier of terminations. Immediately upon crossing the lower border of layer IV, labeled thalamocortical axons branched repeatedly, often forming very fine terminal branches 

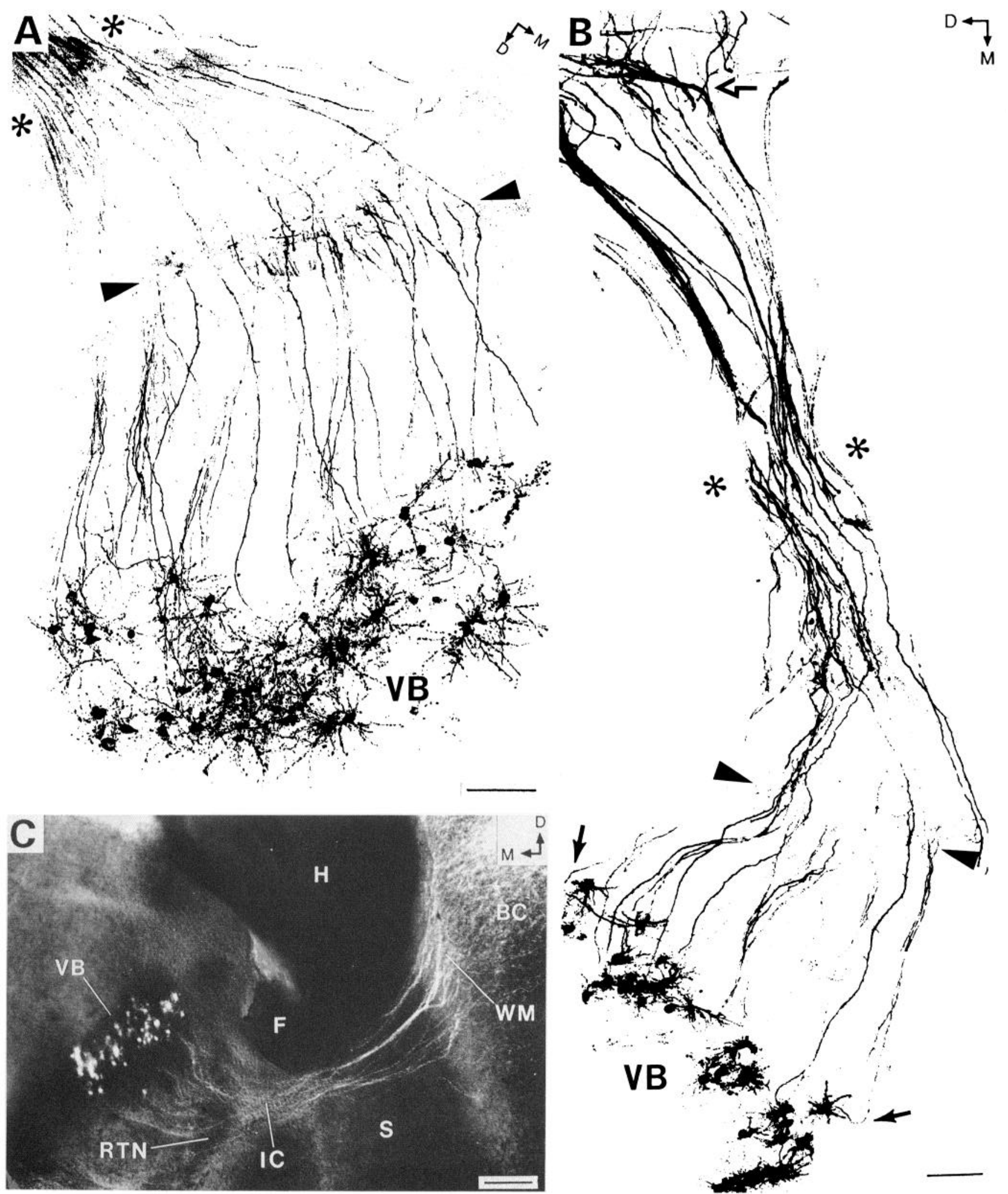

Figure 4. Labeling patterns resulting from focal dye injections in layer IV. $A$, P4 slice; $B$, P5 slice. Arrowheads in $A$ and $B$ delimit regions with thalamocortical collateral ramifications in RTN. Asterisks indicate the convergence of thalamocortical axons in the internal capsule. In $B$, solid arrows in VB point to two axons that make a $90^{\circ}$ course correction a short distance away from their cell body; open arrow indicates deep border of subcortical white matter. $C$, A low-power view of the slice in $B$, rotated $90^{\circ}$ clockwise. Injection site is outside top right corner of the image. $V B$, ventrobasal complex; $R T N$, thalamic reticular nucleus; $I C$, internal capsule; $S$, striatum; $F$, fimbria; $H$, hippocampus; $W M$, subcortical white matter; $B C$, barrel cortex. Direction arrows are as in Figure 1. Scale bars: $A$ and $B, 100 \mu \mathrm{m} ; C, 250 \mu \mathrm{m}$. 


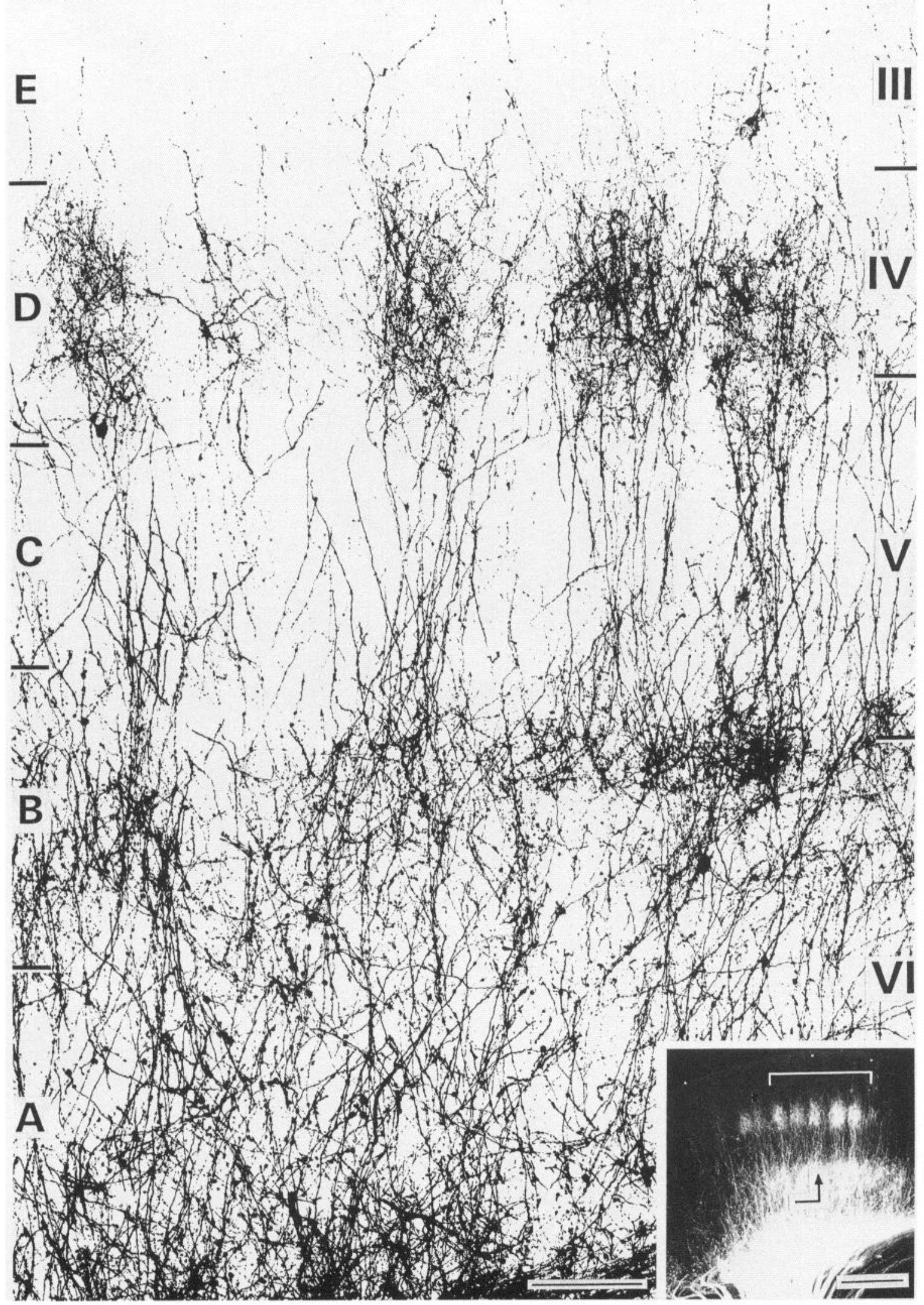

Figure 5. The five zones (labeled on left $A-E$, from white matter to pial surface) defined by labeled thalamocortical afferents in the barrel cortex; anterior-face view of a P8 slice bulk labeled from VB. Laminar borders are marked on right. From the white matter upward, the first zone consists of a dense meshwork of unbranched fibers; the second zone is the lower tier of terminations at the layer VI/V border; the third zone consists of radially coursing axons in upper layer V organized in loose bundles; the fourth zone is the upper tier of terminations in layer IV; and the fifth zone consists of relatively sparse, mainly unbranched terminal segments of axons in layers II-III. Scale bar, $100 \mu \mathrm{m}$. Inset, Low-power image of the same slice; bracket marks the boundaries of the high-power montage. Right-angled arrow is as in Figure $3 \mathrm{~A}$. Scale bar, $500 \mu \mathrm{m}$. 
Figure 6. Deep cortical elements of the thalamocortical pathway. $A-D$, Representative modes of entry of thalamocortical axons from the white matter into the cortex, from $\mathrm{P} 4(A, D), \mathrm{P} 2(B)$, and $\mathrm{P} 3(C)$ slices. Straight arrows point to fibers entering the cortex at shallow $(A)$, right $(B)$, or acute $(C)$ angles, or (rarely) by T-branching (D). $A$ and $D$ are P-face images; $B$ and $C$ are A-face images (note right-angled orientation arrows, as in Fig. 3A). $E$ Labeled thalamocortical axons in a P2 slice. One axon (arrows) coursed tangentially for about $500 \mu \mathrm{m}$ in upper layer VI, before turning upward at a right angle and ascending toward layer IV. This axon was tracked through 30 optical sections (at $5 \mu \mathrm{m}$ spacings) and was never observed to emit branches along its tangential course; near the point of upward turn (upper right corner) it emitted several local terminal branches. Scale bar (in $E$ ): $50 \mu \mathrm{m}$ for $A, D$, and $E ; 65 \mu \mathrm{m}$ for $B$ and $C$.
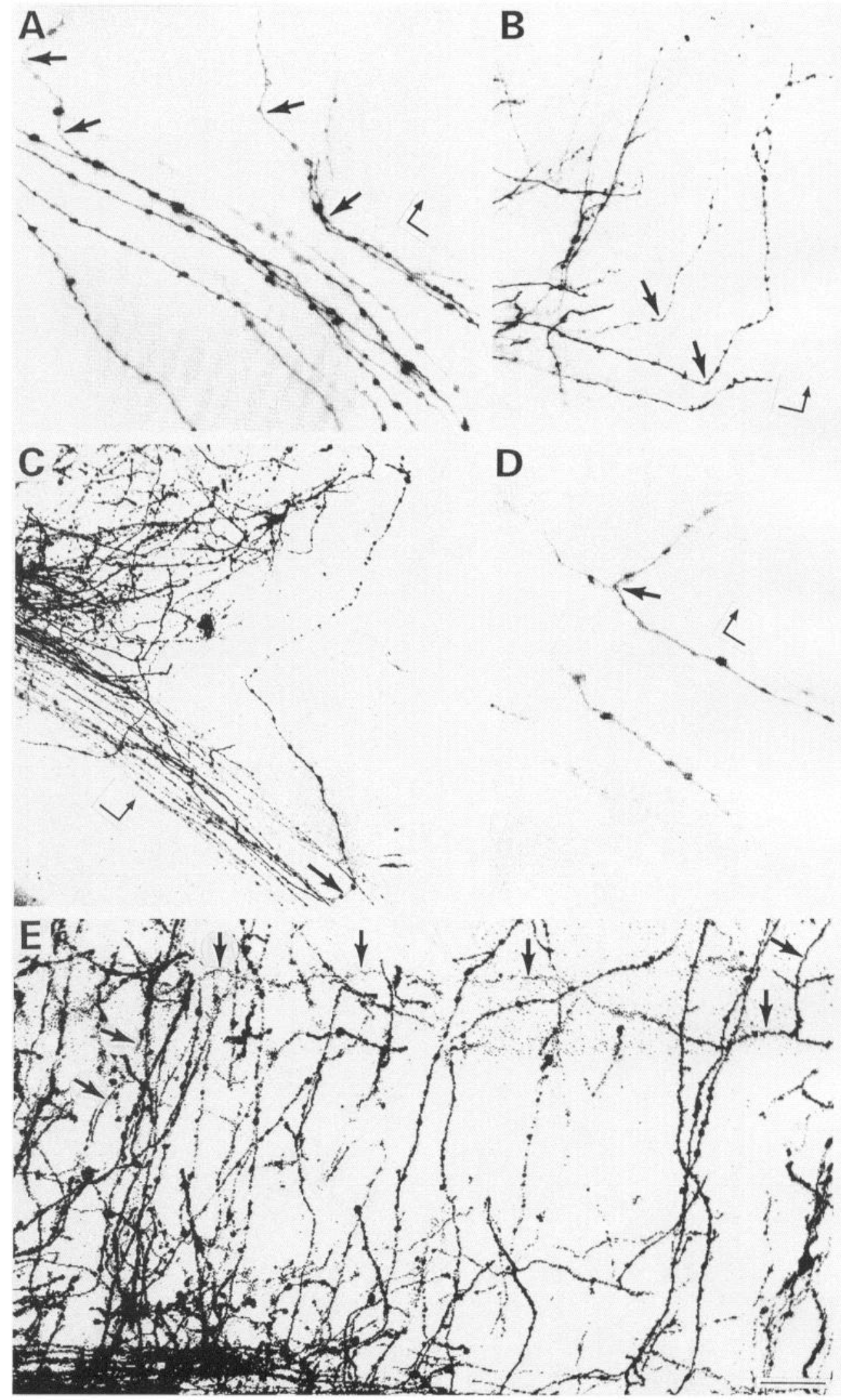

that were difficult to image. Axons from the same bundle formed overlapping arbors, resulting in dense clusters of terminal arborizations (Fig. 5, zone D; Fig. 7B). The width of a cluster in layer IV was commonly no greater than the width of the axonal bundle in upper layer $\mathrm{V}$ leading to it, implying that axons at the margins of each bundle arborized asymmetrically, their branches being directed preferentially toward the center of the bundle. In a few preparations such asymmetric arborizations 


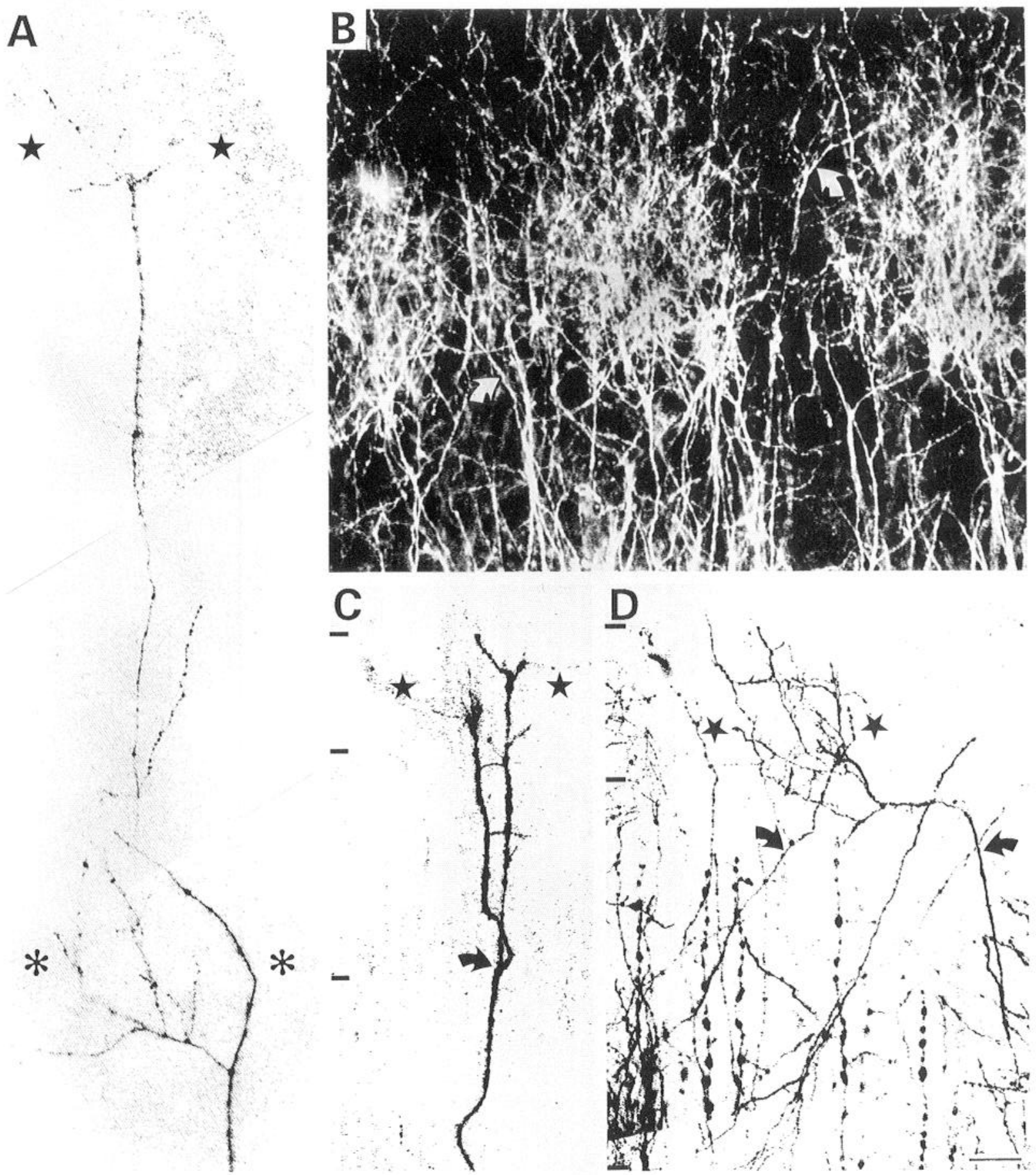

Figure 7. Intracortical branching patterns of thalamocortical axons. A, A P11 thalamocortical axon with both lower-tier (between asterisks) and upper-tier (between stars) arbors. Upper-tier arbor is partially truncated. B, Layer IV clusters of thalamocortical terminations in a P12 preparation. Curved arrows point to axons (a minority) that appear to cross between adjacent clusters. $C, \mathrm{~A}$ thalamocortical axon from a P3 preparation bifurcating below the lower border of layer IV (curved arrow), with the two branches forming overlapping arbors in layer IV (between stars). Markings on left denote laminar borders: from top to bottom, III/IV, IV/V, and V/VI. D, two thalamocortical axons in a P8 slice, ascending separately in upper layer V (curved arrows) but forming overlapping arbors in layer IV (between stars). Laminar borders are as in $C$. Pial surface is up in all panels. Scale bar, $50 \mu \mathrm{m}$.

were observed directly (Fig. $7 D$, between stars). An occasional labeled axon coursed tangentially along layer IV, from one cluster or bundle to an immediately adjacent one (Fig. $7 B$, arrows).

Layers II-III: unbranched terminations. The dense terminal arborizations came to an abrupt end at the upper border of layer IV, but a few labeled axons continued beyond this border and ended in layers II-III, with little or no branching (Fig. 5, zone E). From our material, it could not be determined what fraction of the labeled axons in any layer IV cluster contributed branches to this zone.

\section{Stages in the development of thalamocortical arborizations}

In this section we describe in chronological order the sequence of development of thalamocortical arborizations in mouse bar- 
PO :
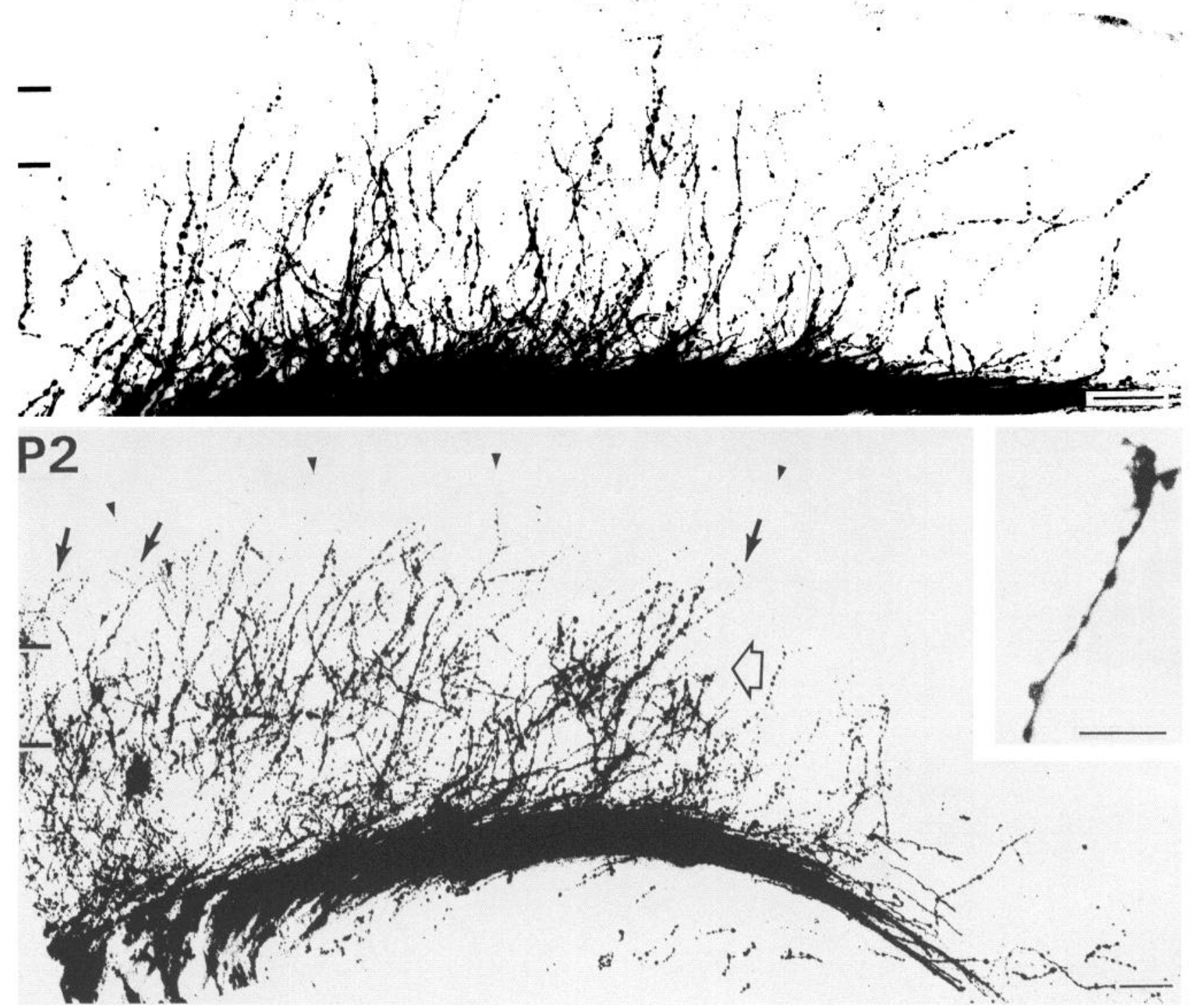

Figure 8. Montages of labeled thalamocortical axons on P0 and P2. This and all subsequent montages are A-face views, oriented with pial surface at $t o p$, white matter at bottom, and axons in the white matter running from ventrolateral (left) to dorsomedial (right). P0, Mostly unbranched axons extend through layers VI and V. P2, A deep tier of terminations is evident (open arrow); above it axons extend roughly radially into nascent layer IV where rudimentary arbors are seen (solid arrows). Arrowheads denote pial surface. Markings at left denote the cortical plate/V and V/VI borders. Inset, A growth cone at the tip of a thalamocortical axon from another P2 specimen. Scale bars: $P 0$ and $P 2,100 \mu \mathrm{m} ;$ inset, $25 \mu \mathrm{m}$.

rel cortex. For expediency of description, we divided the period under study into four stages. The description will focus on the new elements added at each stage; however, growth was cumulative, so at any given stage the pathway contained also all the components of previous stages. Representative preparations from the four stages are shown in Figures 8-10.

$P 0-P 1$. On P0-P1 the tips of the labeled thalamocortical axons formed a front that extended through about two-thirds of the distance from white matter to pial surface (Fig. 8, top), a region corresponding at this stage to layers VI and V (Fig. 2). At the deeper part of the cortex, unbranched labeled fibers entering from the white matter coursed in all directions, forming a dense meshwork. A small number of labeled fibers penetrated the overlying undifferentiated cortical plate and reached the pial surface (not shown).

$P 2-P 3$. At this age the labeled axonal front was much closer to the pial surface (Fig. 8, bottom). Comparison with the Nissl material (Fig. 2) indicated that the majority of labeled thalamocortical axons still extended no farther than the lower border of the undifferentiated cortical plate; however, at this stage the latter was much closer to the pial surface, having receded due to differentiation of cells belonging to layers V and VI. The newly formed lower tier of thalamocortical terminations could be identified as a region with distinctly denser label than regions immediately below and above it, approximately one-third the distance between white matter and pial surface (Fig. 8, bottom, 


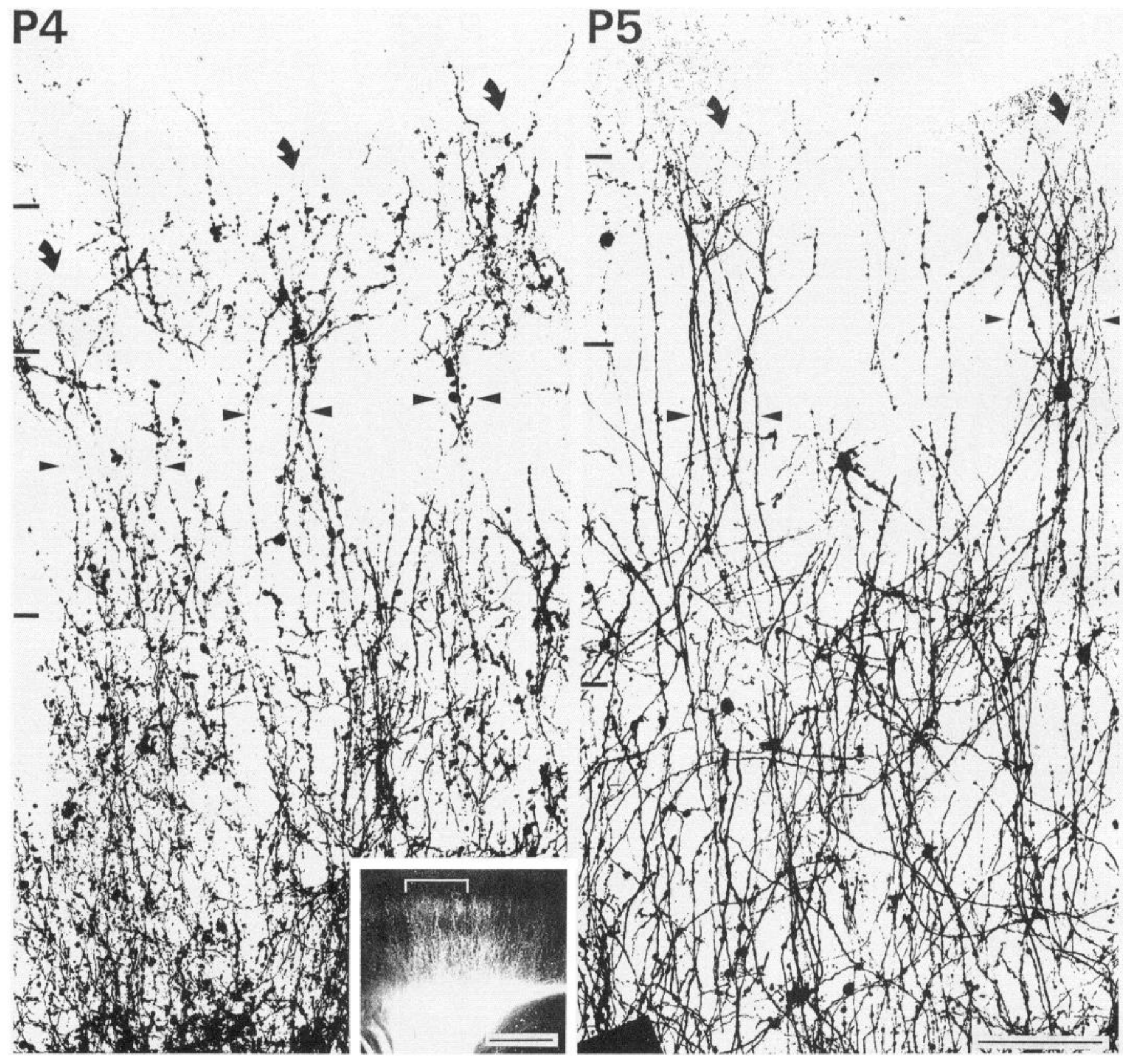

Figure 9. Montages of labeled thalamocortical axons in a P4 (left) and a P5 (right) slice. Note periodic clusters of thalamocortical terminations within layer IV (curved arrows). Arrowheads delimit bundles of labeled thalamocortical axons traversing upper layer V. Markings at left denote the layer III/IV, IV/V, and V/VI borders. Inset, A low-power image of the P4 preparation, with upper boundaries of montage marked by a bracket. Scale bars: $P 4$ and $P 5,100 \mu \mathrm{m}$; inset, $500 \mu \mathrm{m}$.

open arrow). Within or immediately below this zone, some labeled axons were seen to course in a tangential direction, sometimes for several hundred micrometers. When such axons were followed through consecutive optical sections, they were occasionally observed to emit local terminal branches, but were never observed to send multiple ascending branches toward the upper layers (Fig. 6E). Labeled axons above this zone coursed in a general radial direction and terminated in the incipient layer IV, in which some of them formed rudimentary arborizations (Fig. 8, bottom, solid arrows). Other axons ended as unbranched tips or, very rarely, as expanded growth cones (Fig. 8 , inset). Expanded growth cones were never observed later than
P2. In P3 specimens, labeled arbors in layer IV were more elaborate (not shown); however, in none of the P2-P3 preparations did we find the clear clustering of terminal arbors that characterized layer IV at all later ages.

$P 4-P 5$. Although it remained mostly within layer IV, the front of labeled thalamocortical axons was at this stage farther away from the pial surface than at the previous stage, due to the transformation of most of the undifferentiated cortical plate into layers IV and II-III (Fig. 2). Layer IV was clearly recognizable by the dense thalamocortical terminations, which were organized in clusters approximately $100-150 \mu \mathrm{m}$ in width, consisting of overlapping arbors of several axons (Fig. 9, curved arrows). 


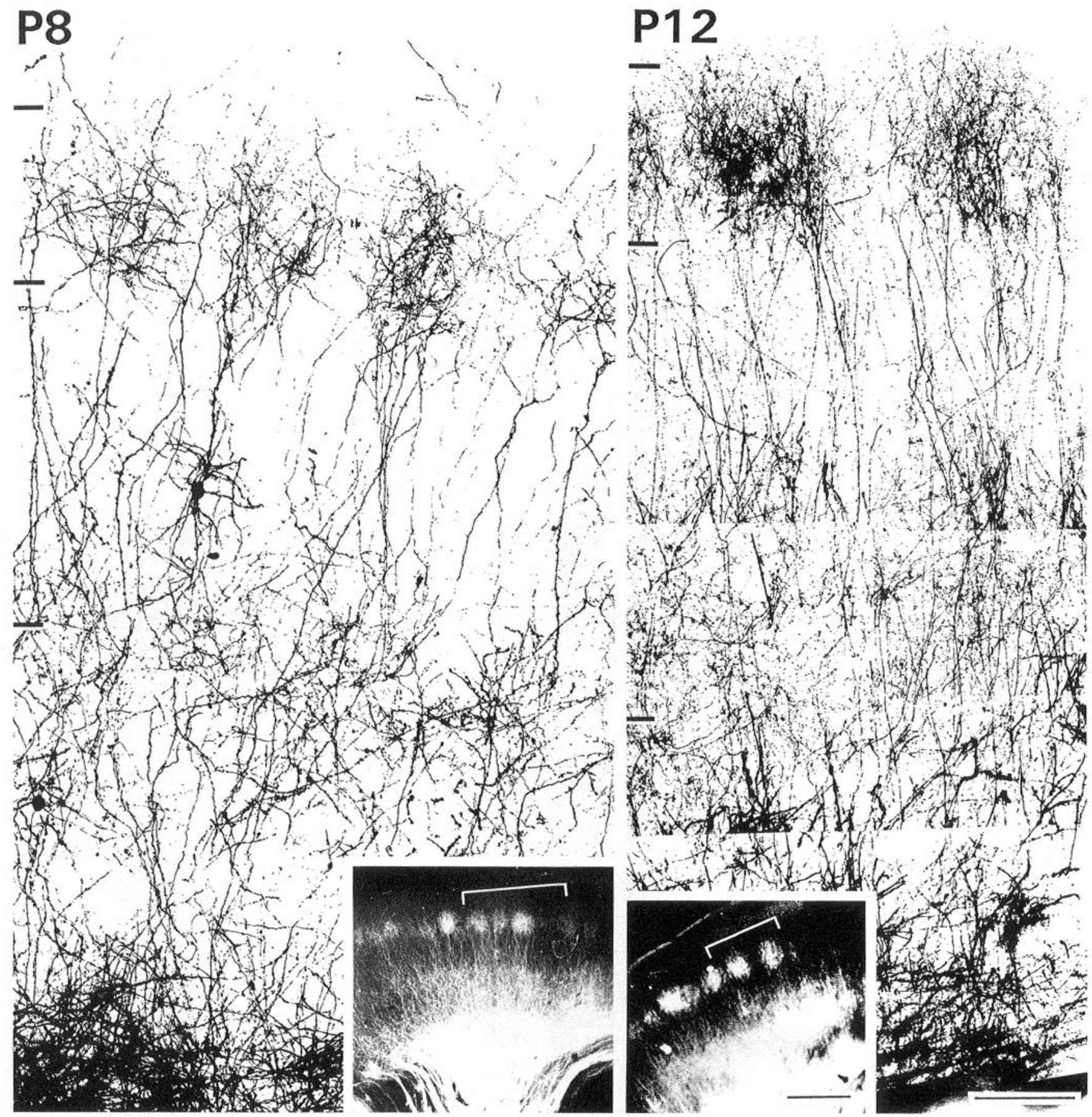

Figure 10. Montages of labeled thalamocortical fibers in P8 (left) and P12 (right) slices. Note increased density of labeled terminal clusters in layer IV on P12 as compared with P8, and on P8 as compared with P4-P5 (Fig. 9). Markings at left denote the layer III/IV, IV/V, and V/VI borders. Insets are low-power images of the same slices with upper boundaries of montages marked by brackets. Scale bars: P8, $100 \mu$ m; PI2, 125 $\mu \mathrm{m}$; insets, $500 \mu \mathrm{m}$.

The labeled axons terminating in a particular cluster appeared to course through upper layer $\mathrm{V}$ together, in a loose bundle (Fig. 9 , between arrowheads). There was little exchange of fibers between bundles. The pattern of thalamocortical terminations at this stage exhibited for the first time clear-cut periodicities, both in layer IV (clusters of terminations) and in upper layer V (radial bundles). Unbranched terminal portions of axons emerged upward from layer IV into layers II-III.

$P 6-P 12$. At this stage there was no further change in the laminar extent of the front of labeled thalamocortical axons. The main changes relative to the previous stage were the increased density of labeled thalamocortical terminations, both in the lower tier and, more strikingly, in the upper tier (Fig. 10). The increase in density of labeled terminations in layer IV continued at least until P12, and could have resulted from an increase in the number of labeled axons contributing to each cluster, from an increase in the complexity of arborizations made by individual axons, or both. By focal injections of DiI in VB 
P4.
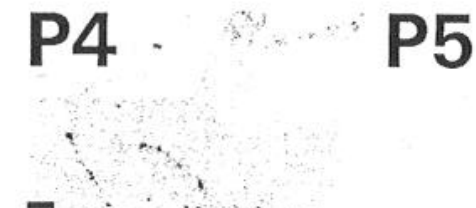

P7

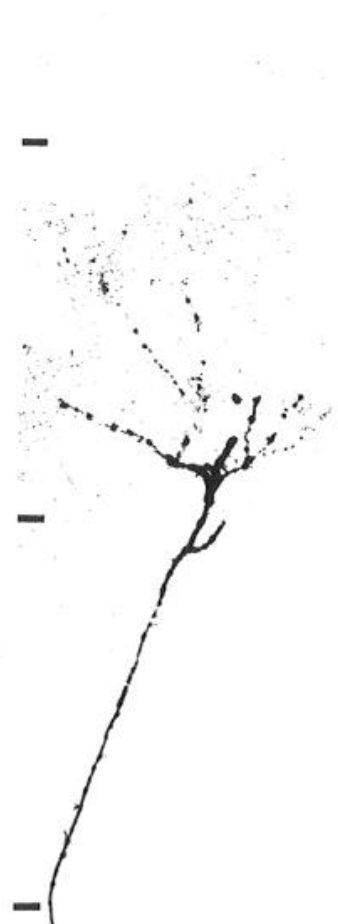

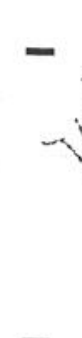

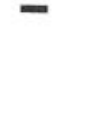

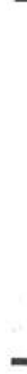
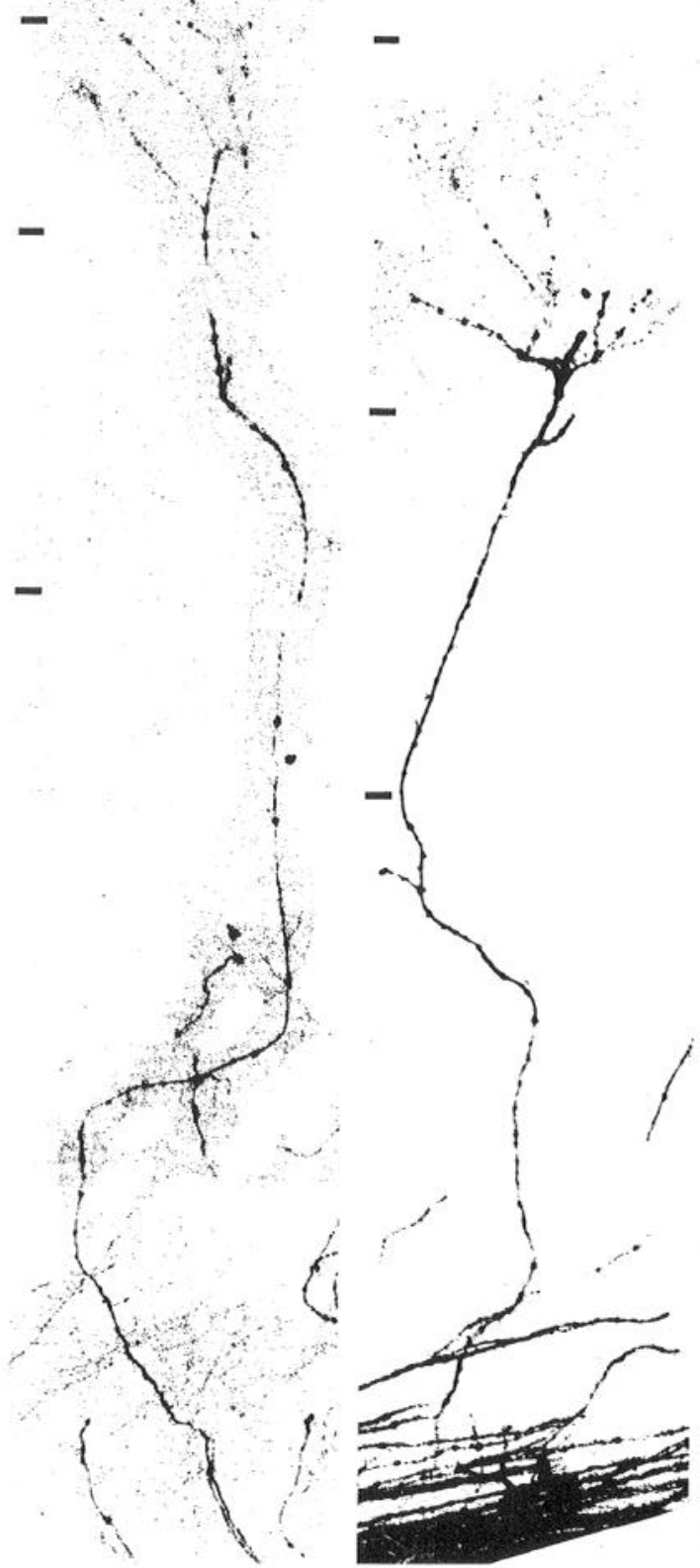

Figure 11. Elaboration of layer IV arbors increases with postnatal age. Individual thalamocortical axons (ages marked) were labeled by focal injections of DiI in VB. Image of the P8 arbor includes a minor contribution from an adjacent axon. Markings at left of each panel denote the layer III/IV, IV/V, and V/VI borders. Scale bar: P4, P5, and P7, $100 \mu \mathrm{m} ; P 8,120 \mu \mathrm{m}$.

we were able to label a small number of thalamocortical axons in isolation for their full intracortical extent (Fig. 11). Examination of these isolated axons clearly revealed an age-dependent increase in the complexity of layer IV arbors of individual axons. This accounted for at least some of the increased density of labeled clusters seen in bulk-labeled specimens.

\section{Discussion}

In the present study we combined DiI labeling in a slice preparation and confocal imaging of whole-mounted specimens to examine, at high spatial resolution, the development of the thal- amocortical termination pattern in neonatal mouse barrel cortex. The developmental sequence derived from our material is shown schematically in Figure 12. On the day of birth unbranched thalamocortical axons extended mostly through layers VI and V. The lower tier of thalamocortical terminations, straddling the layer VI/V border, as well as a rudimentary upper tier in layer IV, were identifiable by P2. On P4 the upper tier of terminations was well developed and consisted of periodic clusters of arbors. The density of the two tiers continued to increase for at least one more week. From their first appearance on P4, clusters of arbors in layer IV arose from loose bundles of radially 


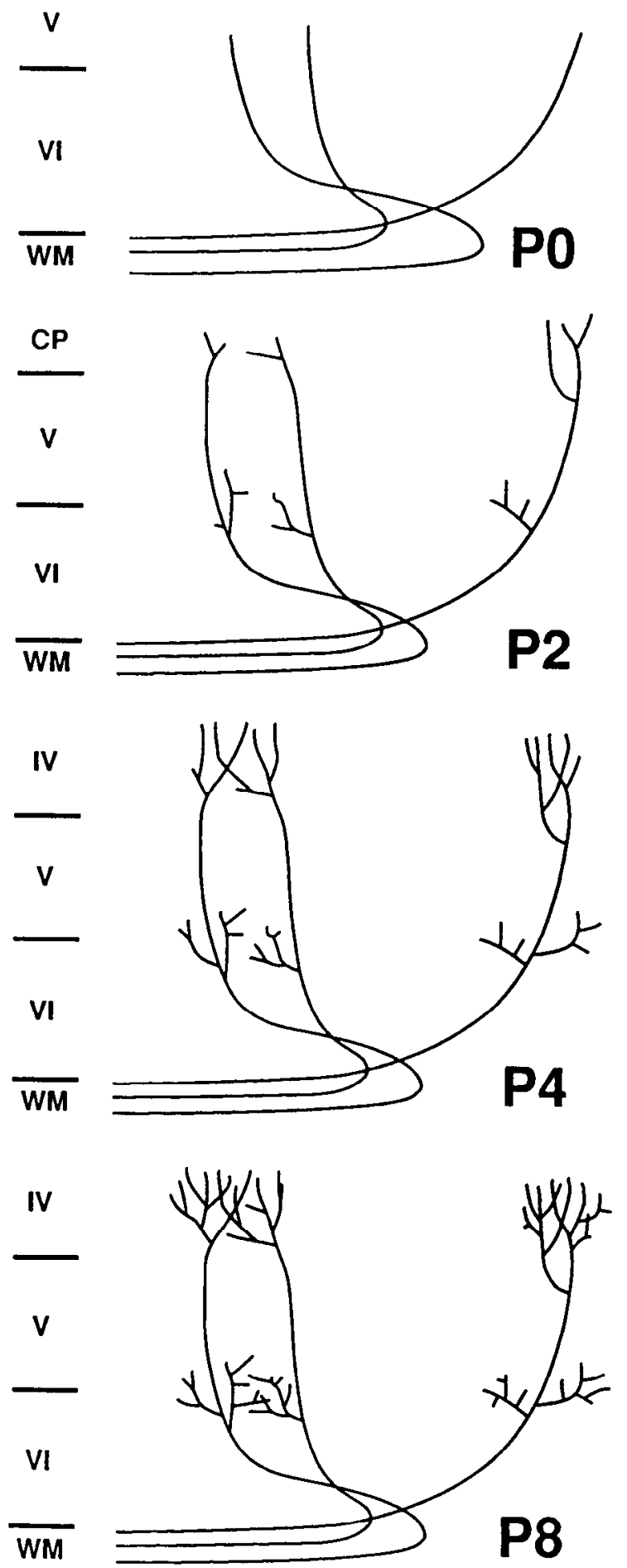

Figure 12. A schematic interpretation of the four stages in the development of thalamocortical terminations in the barrel cortex. On $P O$ unbranched axons extend through the deep layers. By $P 2$ thalamocortical axons have established the lower tier of terminations. From there they ascend radially through upper layer $V$ into nascent layer IV, where rudimentary branches are found. By $P 4$ periodic dense clusters of thalamocortical arbors have formed in layer IV, comprising the upper tier of terminations. Density of the two tiers continues to increase until at least P12. $C P$, cortical plate; $W M$, white matter. oriented fibers traversing upper layer V. Within layer IV fibers from any individual bundle were for the most part confined to a single cluster. The radial orientation of fibers ascending from the lower to the upper tier, and their termination in individual clusters within the upper tier, suggested that axons destined to innervate a particular layer IV barrel were already in their correct tangential position before leaving the lower tier. Thus, the pattern of thalamocortical terminations in layer IV seems to be derived from an earlier established order in the lower tier of terminations, and not from remodeling of an initially diffuse pattern within layer IV.

\section{Methodological issues}

In the present study the lipophilic dye DiI (Godement et al., 1987) was placed in $400-\mu \mathrm{m}$-thick, fixed slices, rather than in intact brains or hemispheres. This allowed precise placement of dye under direct visual control, into structures as small as single cortical barrels. The plane of section was chosen based on electrophysiological studies that demonstrated the continuity of thalamocortical connections in slices cut along this plane (Agmon and Connors, 1991). Placing the dye in a slice, rather than in an intact brain, resulted in labeling of a limited portion of the pathway, because (1) only a portion of VB was contained within the $400 \mu \mathrm{m}$ thickness of the slice; (2) of those VB cells that were included in the slice, many undoubtedly had axons that were truncated before reaching the cortex. The resulting lower density of labeled fibers in the cortex allowed us to follow the intracortical course of individual fibers for considerable distances. Another important advantage of our method was the separation achieved between labeled afferent and efferent fibers, thus removing potential ambiguity about the identity of labeled processes (see below).

\section{Identification of labeled processes}

The conclusions derived from our material were based on the premise that the great majority of labeled processes we encountered in the cortex after dye placements in VB were axons originating in VB. Fibers from the POm are known to pass through VB on their way to the barrel cortex; however, they terminatc in the cortex in a pattern that is complementary to the pattern of termination of afferents originating in VB (Koralek et al., 1988; Nothias et al., 1988; Chmielowska et al., 1989; Fabri and Burton, 1991). This implies that labeling of POm axons would tend to mask the whisker-related periodicity exhibited by VB axons. The pronounced periodicity in the pattern of labeled terminations in layer IV in our material therefore suggests that few, if any, labeled POm axons were found in our slices. Retrogradely labeled corticothalamic cells and their intracortical axons were mostly excluded from our images due to the segregation of efferents and afferents in opposite faces of the slice (next section).

\section{The separation between afferent and efferent pathways}

Following placement of dye in VB, labeled thalamocortical fibers were concentrated near the A-face of the slice, while retrogradely labeled corticothalamic fibers and their cell bodies were concentrated near the P-face (Fig. 3). This was unexpected, in view of the well-established reciprocity between the two pathways (reviewed by Jones, 1985). Indeed, a small placement of dye in VB in the whole animal results in an overlap of anterogradely and retrogradely labeled elements in the cortex (Colwell, 1975). The segregation of anterogradely and retrogradely 
labeled elements when the same experiment was performed in a slice could have resulted from the fact that thalamocortical and corticothalamic axons that connect corresponding thalamic and cortical loci are following different trajectories between these loci. This would cause differential truncation of the two sets of axons during the slicing procedure, resulting in an apparent segregation. This separation between thalamocortical and corticothalamic fibers would suggest that, at least in the barrel cortex, the two systems of fibers do not guide each other during development, as has been suggested to occur in other systems (McConnell et al., 1989; Blakemore and Molnar, 1990).

\section{Establishment of order in the lower tier precedes the emergence of pattern in the upper tier: a hypothesis}

Our data showed that most of the axons forming the layer IV clusters ascended through upper layer $V$ in a straight and radial course, and that within layer IV most axons remained confined to one cluster. These features made it unlikely that an axon would change its cluster of destination once it had left the lower tier of terminations. It follows that an ordering of axons according to their cluster of destination must have already taken place within (or below) the lower tier. We conclude that the development of the thalamocortical termination pattern is a two-stage process. In the first stage, thalamocortical axons rearrange in a somatotopic "protomap" while still in the deep layers. This protomap may be a continuous representation, or may already have a whisker-related periodicity. In the second stage thalamocortical axons ascend to layer IV, where they form a discontinuous projection pattern. A testable prediction of this hypothesis is that somatotopic order in the deep layers of barrel cortex should be retained when the projection to layer IV is selectively inactivated.

The alternative to this hypothesis is that thalamocortical axons first rearrange in somatotopic order within layer IV, not in the deep tier of terminations. This would require them to probe layer IV during development, in search of their correct final location. Branches that found themselves in the "wrong" position would then be retracted or "pruned," while branches in correct locations would be stabilized and develop mature arbors. The only way thalamocortical axons could probe wide regions of layer IV, and still maintain a general radial direction in layer $\mathrm{Va}$, would be by either (1) coursing tangentially within layer IV for long distances, or (2) coursing tangentially within the deep layers (or the white matter), and sending multiple vertical branches upward into layer IV. Our results seem incompatible with both possibilities. If axons reached their correct location by traveling along layer IV, one would find many tangentially coursing axons within laycr IV in the mature system, and this is not the case. Similarly, when imaging single axons in isolation (Fig. 11), or in tracking individual axons through several hundred micrometers of their intracortical trajectories in the deep layers (Fig. $6 E$ ), we never observed any, even at the youngest ages, that sent multiple vertical branches into presumptive or definitive layer IV. Although some axons were observed to emit branches within the lower tier (Figs. $6 E, 7 A$ ), these were always confined to one locale and did not ascend above lower layer $V$. While we cannot categorically rule out the possibility that, during a developmental period too brief to be captured in our material, some thalamocortical axons did emit multiple, widely spaced branches that reached layer IV, our inability to find a single example of this type in our study, as well as in the published literature (see below), strongly suggests that such a mode of branching was not a general phenomenon that could underlie the formation of the mature termination pattern.

\section{Comparison with previous studies in the rodent}

Several previous studies have followed the development of thalamocortical axons in the barrel cortex of the perinatal rodent (Wise and Jones, 1978; Erzurumlu and Jhaveri, 1990; Catalano et al., 1991; Senft and Woolsey, 1991a). Comparable studies have been undertaken in the rodent visual cortex (Lund and Mustari, 1977; Naegele et al., 1988; Kageyama and Robertson, 1993). Wise and Jones (1978) labeled thalamocortical fibers in neonatal rats by anterogradely transported radioactive amino acids. They reported that on $\mathrm{P} 0$, labeled thalamocortical axons had reached upper layer VI. By P2 there was label in the emergent layer IV at the lower border of the dense cortical plate, and by late P3 there was a clearly recognizable band of terminations in layer IV, resulting in a double-tiered distribution of label. Although commonly quoted to the contrary, this study did not state that thalamocortical axons in the neonatal rat "wait" in the white matter before entering the cortex, but conjectured that a waiting period could occur prenatally. A prenatal waiting period was recently ruled out in both somatosensory and visual cortices in the rat (Catalano et al., 1991; Kageyama and Robertson, 1993). Erzurumlu and Jhaveri (1990) used DiI to label thalamocortical axons in fixed brains of perinatal rats. In their P0 material, thalamocortical axons were found to occupy layers $\mathrm{VI}$ and $\mathrm{V}$, with sporadic axons penetrating the overlying cortical plate. In tangential sections, a crude vibrissae-related pattern was already apparent in P2 material, and a mature-like pattern emerged by P4. Senft and Woolsey (1991a) examined the development of the thalamocortical pathway in the mouse by labeling large number of axons with HRP in live slices, and with DiI in fixed brains. They proposed that developing thalamocortical axons initially arborize profusely, each axon sending branches into several presumptive barrels, and that this diffuse projection is subsequently remodeled to the adult pattern (Senft and Woolsey, 1991b, Fig. 7; Senft and Woolsey, 1991c, Fig. 10). However, the axons shown by Senft and Woolsey (1991a), including those that emitted several branches in the deep layers, sent at most a single branch into layer IV (or its precursor).

Compared with these previous studies, the present investigation has achieved a higher spatial resolution, has imaged a number of axons in isolation throughout their full intracortical course, has achieved an unambiguous identification of anterogradely versus retrogradely labeled elements, and has followed the developing thalamocortical pathway during a longer postnatal time span. The developmental sequence that emerged is, in general, consistent with previous findings; however, our data call for reinterpretation of some previous results and for reevaluation of some previous conclusions. A point in question is the laminar location of whisker pad-like patterns seen with various staining methods. Our data show barrel-related bundling of thalamocortical axons in upper layer $\mathrm{V}$, and imply the existence of somatotopic order within the deep tier of terminations. It follows that in a tangential plane of section, a whiskerrelated pattern may be encountered not only in layer IV but also in layer $\mathrm{V}$ and in upper layer VI. Thus, reports of barrel-field pattern in P2 or younger animals (Steindler et al., 1989; Erzurumlu and Jhaveri, 1990; Schlaggar and O'Leary, 1991), when layer IV is still undifferentiated, may in fact reflect a pattern that exists in the deep layers. Periodicity within the deep tier is not apparent in our material, presumably because it is obscured 
by the many tangentially and obliquely running fibers within the lower tier of terminations; it would be more apparent in a tangential plane of section, and with methods that specifically stain axon terminals.

As discussed above, our findings do not support the hypothesis suggested by Senft and Woolsey $(1991 \mathrm{a}-\mathrm{c})$, that developing thalamocortical axons initially branch profusely across a wide tangential extent, and that the mature pattern in layer IV is achieved by elimination of exuberant branches. Thalamocortical axons travel tangentially or obliquely over a wide horizontal extent in the deep layers, as reported by Senft and Woolsey (1991a), but at no stage do they appear to send multiple branches toward the superficial layers. Thus, the anatomical substrate for a subsequent pruning process does not seem to exist.

\section{Comparison with previous studies in the cat}

In a DiI study of the developing cat thalamocortical pathway, Ghosh and Shatz (1992b) found that, during a prenatal "waiting" period of about 2 weeks, thalamocortical axons formed a dense plexus of terminal branches within the visual cortex subplate, before invading the cortical plate itself. The rodent homolog of the cat and monkey subplate is somewhat uncertain. On the basis of early neurogenesis, the subplate nomenclature has recently been applied to sublamina VIb (Bayer and Altman, 1990; Kageyama and Robertson, 1993); however, there is considerable overlap in birthdates between sublamina VIb and sublaminae VIa and Vb (Raedler and Raedler, 1978; Valverde et al., 1989; Bayer and Altman, 1990). Branching of thalamocortical axons occurs in the rodent in the vicinity of the layer V/VI border and not in lower layer VI. Ablation experiments (Ghosh et al., 1990; Ghosh and Shatz, 1992a) suggest that, in cat visual cortex, the cortical subplate plays a vital role both in guidance of developing thalamocortical axons to their correct target area and in establishing a normal pattern of thalamocortical termination in layer IV. According to our hypothesis, at least the second of these two roles would be played in the rodent by sublaminae $\mathrm{VIa} / \mathrm{Vb}$, where the lower tier of terminations is established.

Growth patterns and guidance cues in the thalamocortical and other pathways

Two opposing models of growth have previously been proposed to account for formation of topologically ordered axonal projections in the nervous system. According to the first model, axons arborize only after reaching their final target, and consequently their terminal arborizations are $a b$ initio in the appropriate location and the ensuing topology is precise from the inception of the projection. According to the alternative model, axons initially form profuse terminal arborizations and consequently a crude topology, which is subsequently refined through a process of selective pruning. There are numerous examples for both modes of growth. Directed growth seems to occur in the retinotectal pathways of fish and amphibians during normal development (Holt and Harris, 1983; Sakaguchi and Murphey, 1985; Fujisawa, 1987; Kaethner and Stuermer, 1992), while remodeling of an initially profuse projection has been reported in the same pathways during regeneration (Meyer, 1980; Stuermer and Easter, 1984). A well-known example for pruning of a profuse projection is the segregation of axonal terminations into eye-specific domains, occurring in both thalamus and cortex of binocular mammals (LeVay et al., 1978, 1980; Sretavan and Shatz, 1986), as well as in the tectum of the threc-cyed frog
(Constantine-Paton and Law, 1978). The mechanisms underlying these two modes of growth are thought to be different. Directed growth of axons is thought to be guided by positional and directional cues in the target tissue, for example, molecular gradients (Gierer, 1987), while remodeling of profuse axonal arborizations is thought to depend on fiber-fiber interactions, for example, activity-mediated competition (Willshaw and von der Malsburg, 1976). In agreement with these hypotheses, impulse blockade does not prevent retinotopic connections in fish and amphibians from developing normally (Harris, 1984; Stuermer et al., 1990), but prevents refinement of the retinotopic map during regeneration (reviewed by Schmidt, 1985), and similarly prevents segregation of axon terminations into eye-specific domains in LGN, visual cortcx, and tectum (reviewed by Shatz, 1990).

As follows from the previous discussion, we believe that development of the thalamocortical projection pattern in layer IV of mouse barrel cortex follows the model of directed growth, not of profuse arborization. Recent experiments indicate that barrel formation in the rodent can occur normally during blockade of cortical activity or of peripheral inputs (Chiaia et al., 1992; Henderson et al., 1992). These findings strongly suggest that the periodicity of axonal terminals in layer IV of barrel cortex does not arise from activity-dependent competitive interactions between thalamocortical terminals, in agreement with the directed growth model proposed here. It should be emphasized that our hypothesis pertains to the upper tier of terminations only; our data do not rule out the possibility that somatotopic order in the lower tier is derived from selective pruning of an initially profusc projection. In the lower tier such a process may occur prenatally, and thus may not be affected by the postnatal manipulations employed in the two studies cited above.

Our data suggest that, once somatotopic order is established in the deep layers, it is projected onto layer IV by radially directed extension of thalamocortical axons. This radial growth could be induced by a diffusible chemotropic signal secreted from layer IV neurons. Chemotropic signals have been suggested to guide developing axons in other CNS pathways (Tessier et al., 1988; Heffner et al., 1990). The existence of a layer IVspecific guidance signal is also suggested by in vitro experiments, in which thalamic axons growing into cortical explants appeared to locate and arborize in layer IV, regardless of the spatial relationships between the two explants (Molnar and Blakemore, 1991; Bolz et al., 1992; Yamamoto et al., 1992). The search for putative guidance molecules will require a system in which the development of the pathway can be manipulated experimentally. The thalamocortical slice, maintained in vitro, may be one system in which such manipulations could be performed successfully.

\section{References}

Agmon A, Connors BW (1991) Thalamocortical responses of mouse somatosensory (barrel) cortex in vitro. Neuroscience 41:365-379.

Bayer SA, Altman J (1990) Development of layer I and the subplate in the rat neocortex. Exp Neurol 107:48-62.

Blakemore C, Molnar Z (1990) Factors involved in the establishment of specific interconnections between thalamus and cerebral cortex. Cold Spring Harbor Symp Quant Biol 55:491-504.

Blue ME, Erzurumlu RS, Jhaveri S (1991) A comparison of pattern formation by thalamocortical and serotonergic afferents in the rat barrel field cortex. Cereb Cortex 1:380-389.

Bolz J, Novak N, Staiger V (1992) Formation of specific afferent connections in organotypic slice cultures from rat visual cortex cocultured with lateral geniculate nucleus. J Neurosci 12:3054-3070. 
Catalano SM, Robertson RT, Killackey HP (1991) Early ingrowth of thalamocortical afferents to the neocortex of the prenatal rat. Proc Natl Acad Sci USA 88:2999-3003.

Chiaia NL, Fish SE, Bauer WR, Bennett CC, Rhoades RW (1992) Postnatal blockade of cortical activity by tetrodotoxin does not disrupt the formation of vibrissa-related patterns in the rat's somatosensory cortex. Dev Brain Res 66:244-250.

Chmielowska J, Carvell GE, Simons DJ (1989) Spatial organization of thalamocortical and corticothalamic projection systems in the rat SmI barrel cortex. J Comp Neurol 285:325-338.

Colwell SA (1975) Thalamocortical-corticothalamic reciprocity: a combined anterograde-retrograde tracer technique. Brain Res 92:443449.

Constantine-Paton M, Law MI (1978) Eye-specific termination bands in tecta of three-eyed frogs. Science 202:639-641.

Cooper NG, Steindler DA (1986) Lectins demarcate the barrel subfield in the somatosensory cortex of the early postnatal mouse. J Comp Neurol 249:157-169.

Dodd J, Jessel TM (1988) Axon guidance and the patterning of neuronal projections in vertebrates. Science 242:692-699.

Erzurumlu RS, Jhaveri S (1990) Thalamic axons confer a blueprint of the sensory periphery onto the developing rat somatosensory cortex. Dev Brain Res 56:229-234.

Erzurumlu RS, Jhaveri S, Benowitz LI (1990) Transient patterns of GAP-43 expression during the formation of barrels in the rat somatosensory cortex. J Comp Neurol 292:443-456.

Fabri M, Burton H (1991) Topography of connections between primary somatosensory cortex and posterior complex in rat: a multiple fluorescent tracer study. Brain Res 538:351-357.

Frost DO, Caviness VS (1980) Radial organization of thalamic projections to the neocortex in the mouse. J Comp Neurol 194:369-393.

Fujisawa H (1987) Mode of growth of retinal axons within the tectum of Xenopus tadpoles, and implications in the ordered neuronal connection between the retina and the tectum. J Comp Neurol 260:127139.

Ghosh A, Shatz CJ (1992a) Involvement of subplate neurons in the formation of ocular dominance columns. Science 255:1441-1443.

Ghosh A, Shatz CJ (1992b) Pathfinding and target selection by developing geniculocortical axons. J Neurosci 12:39-55.

Ghosh A, Antonini A, McConnell SK, Shatz CJ (1990) Requirement for subplate neurons in the formation of thalamocortical connections. Nature 347:179-181.

Gierer A (1987) Directional cues for growing axons forming the retinotectal projection. Development 101:479-489.

Godement P, Vanselow J, Thanos S, Bonhoeffer F (1987) A study in developing visual systems with a new method of staining neurones and their processes in fixed tissue. Development 101:697-713.

Harris WA (1984) Axonal pathfinding in the absence of normal pathways and impulse activity. J Neurosci 4:1153-1162.

Heffner CD, Lumsden AG, O'Leary DD (1990) Target control of collateral extension and directional axon growth in the mammalian brain. Science 247:217-220.

Henderson TA, Woolsey TA, Jacquin MF (1992) Infraorbital nerve blockade from birth does not disrupt central trigeminal pattern formation in the rat. Dev Brain Res 66:146-152.

Herkenham M (1980) Laminar organization of thalamic projections to the rat neocortex. Science 207:532-534.

Holt CE, Harris WA (1983) Order in the initial retinotectal map in Xenopus: a new technique for labeling growing nerve fibers. Nature 301:150-152.

Jhaveri S, Erzurumlu RS, Crossin K (1991) Barrel construction in rodent neocortex: role of thalamic afferents versus extracellular matrix molecules. Proc Natl Acad Sci USA 88:4489-4493.

Jones EG (1985) The thalamus, p 935. New York: Plenum.

Kaethner RJ, Stuermer CA (1992) Dynamics of terminal arbor formation and target approach of retinotectal axons in living zebrafish embryos: a time-lapse study of single axons. J Neurosci 12:32573271 .

Kageyama GH, Robertson RT (1993) Development of geniculocortical projections to visual cortex in rat: evidence for early ingrowth and synaptogenesis. J Comp Neurol 335:123-148.

Killackey HP, Belford GR (1979) The formation of afferent patterns in the somatosensory cortex of the neonatal rat. J Comp Neurol 183: 285-303.

Killackey HP, Leshin S (1975) The organization of specific thala- mocortical projections to the posteromedial barrel subfield of the rat somatic sensory cortex. Brain Res 86:469-472.

Koralek KA, Jensen KF, Killackey HP (1988) Evidence for two complementary patterns of thalamic input to the rat somatosensory cortex. Brain Res 463:346-351.

Kristt DA (1979) Somatosensory cortex: acetylcholinesterase staining of barrel neuropil in the rat. Neurosci Lett 12:177-182.

LeVay S, Stryker MP, Shatz CJ (1978) Ocular dominance columns and their development in layer IV of the cat's visual cortex: a quantitative study. J Comp Neurol 179:223-244.

LeVay S, Wiesel TN, Hubel DH (1980) The development of ocular dominance columns in normal and visually deprived monkeys. $\mathrm{J}$ Comp Neurol 191:1-51.

Lorente de Nó R (1922) La corteza cerebral del ratón. Trab Inst Cajal Invest Biol 20:41-78.

Lund RD, Mustari MJ (1977) Development of the geniculocortical pathway in rats. J Comp Neurol 173:289-306.

McConnell SK, Ghosh A, Shatz CJ (1989) Subplate neurons pioneer the first axon pathway from the cerebral cortex. Science 245:978982.

Meyer RL (1980) Mapping the normal and regenerating retinotectal projection of goldfish with autoradiographic methods. J Comp Neurol 189:273-289.

Molnar Z, Blakemore C (1991) Lack of regional specificity for connections formed between thalamus and cortex in coculture. Nature $351: 475-477$

Naegele JR, Jhaveri S, Schneider GE (1988) Sharpening of topographical projections and maturation of geniculocortical axon arbors in the hamster. J Comp Neurol 277:593-607.

Nothias F, Peschanski M, Besson JM (1988) Somatotopic reciprocal connections between the somatosensory cortex and the thalamic Po nucleus in the rat. Brain Res 447:169-174.

Raedler E, Raedler A (1978) Autoradiographic study of early neurogenesis in rat neocortex. Anat Embryol (Berl) 158:267-284.

Rhoades RW, Bennett-Clarke CA, Chiaia NL, White FA, MacDonald GJ, Haring JH, Jacquin MF (1990) Development and lesion induced reorganization of the cortical representation of the rat's body surface as revealed by immunocytochemistry for serotonin. J Comp Neurol 293:190-207.

Rice FL, Van der Loos H (1977) Development of the barrels and barrel field in the somatosensory cortex of the mouse. J Comp Neurol 171:545-560.

Rice FL, Gomez C, Barstow C, Burnet A, Sands P (1985) A comparative analysis of the development of the primary somatosensory cortex: interspecies similarities during barrel and laminar development. J Comp Neurol 236:477-495.

Sakaguchi DS, Murphey RK (1985) Map formation in the developing Xenopus retinotectal system: an examination of ganglion cell terminal arborizations. J Neurosci 5:3228-3245.

Schlaggar BL, O'Leary DDM (1991) A periphery-related pattern is evident in rat somatosensory cortex at birth. Soc Neurosci Abstr 17: 1126.

Schmidt JT (1985) Formation of retinotopic connections: selective stabilization by an activity-dependent mechanism. Cell Mol Neurobiol 5:65-84.

Senft SL, Woolsey TA (1991a) Growth of thalamic afferents into mouse barrel cortex. Cereb Cortex 1:308-335.

Senft SL, Woolsey TA (1991b) Computer-aided analyses of thalamocortical afferent ingrowth. Cereb Cortex 1:336-347.

Senft SL, Woolsey TA (1991c) Mouse barrel cortex viewed as Dirichlet domains. Cereb Cortex 1:348-363.

Shatz CJ (1990) Impulse activity and the patterning of connections during CNS development. Neuron 5:745-756.

Sretavan DW, Shatz CJ (1986) Prenatal development of retinal ganglion cell axons: segregation into eye-specific layers. J Neurosci 6:234 251.

Steindler DA, Cooper NG, Faissner A, Schachner M (1989) Boundaries defined by adhesion molecules during development of the cerebral cortex: the $\mathrm{J} 1 /$ tenascin glycoprotein in the mouse somatosensory cortical barrel field. Dev Biol 131:243-260.

Stuermer C, Easter SS (1984) A comparison of the normal and regenerated retinotectal pathways of goldfish. J Comp Neurol 223:57-76.

Stuermer CA, Rohrer B, Munz H (1990) Development of the retinotectal projection in zebrafish embryos under TTX-induced neuralimpulse blockade. J Neurosci 10:3615-3626. 
Tessier LM, Placzek M, Lumsden AG, Dodd J, Jessell TM (1988) Chemotropic guidance of developing axons in the mammalian central nervous system. Nature 336:775-778.

Valverde F, Facal VM, Santacana M, Heredia M (1989) Development and differentiation of early generated cells of sublayer VIb in the somatosensory cortex of the rat: a correlated Golgi and autoradiographic study. J Comp Neurol 290:1 18-140.

Willshaw DJ, von der Malsburg C (1976) How patterned neural connections can be set up by self-organization. Proc R Soc Lond [Biol] 194:431-445.
Wise SP, Jones EG (1978) Developmental studies of thalamocortical and commissural connections in the rat somatic sensory cortex. $\mathrm{J}$ Comp Neurol 178:187-208.

Woolsey TA, Van der Loos H (1970) The description of a cortical field composed of discrete cytoarchitectonic units. Brain Res 17:205242.

Yamamoto N, Yamada K, Kurotani T, Toyama K (1992) Laminar specificity of extrinsic cortical connections studied in coculture preparations. Neuron 9:217-228. 